\title{
Published Title: MOVING TOWARDS A GREEN DECOUPLING BETWEEN ECONOMIC DEVELOPMENT AND ENVIRONMENTAL STRESS? A NEW COMPREHENSIVE APPROACH FOR ECUADOR
}

\section{Preprint Title: MITIGATION AND ENERGY EFFICIENCY POLICIES IN ECUADOR}

José M. Cansino ${ }^{1,2, ~ *}$, Antonio Sánchez-Braza ${ }^{3}$, Nereyda Espinoza $^{4}$

${ }^{1}$ Universidad de Sevilla

Departamento de Análisis Económico y Economía Política

Avda. Ramón y Cajal, 1

Postal Code 41018 Sevilla

Spain

E-mail: jmcansino@us.es

Phone: + (34) 9545575 28. Fax: + (34) 954557629

${ }^{2}$ Universidad Autónoma de Chile, Av. Pedro de Valdivia 425, Providencia

Santiago 758-0150, Chile

${ }^{3}$ Universidad de Sevilla

Departamento de Análisis Económico y Economía Política

Avda. Ramón y Cajal 1

Postal Code 41018 Sevilla

Spain

E-mail: asb@us.es

Tel.: + (34) 954557 529. Fax: + (34) 954557629

${ }^{4}$ Escuela Superior Politécnica del Litoral, ESPOL

Facultad de Ciencias Sociales y Humanísticas

Campus Gustavo Galindo Km. 30.5 Vía Perimetral

P.O. Box 09-01-5863, Guayaquil, Ecuador

E-mail: neespino@espol.edu.ec

Tel.: + (593) 2269062

* Corresponding author 


\title{
GREEN HOUSE GASES’ MITIGATION POLICIES IN ECUADOR
}

\begin{abstract}
Focused on Ecuatorian's Economy this article analyzes for the 2000-2014 period. i) What have the drivers of $\mathrm{CO}_{2}$ emission in Ecuador been? ii) What are the determining factors to be focused on with regards to energy policy efforts and the mitigation of GHG emissions? And iii) Is the economy of Ecuador moving towards decoupling between economic growth and environmental stress?

To respond to question i) a decomposition analysis of the change in $\mathrm{CO}_{2}$ emissions has been developed using the LMDI-I model. The decomposing factors or effects used include Carbon Intensity, Renewable Energy Sources penetration, Energy Intensity, Economic Structure, Economic Activity and Population. To answer question ii) a so-called Innovative Accounting Approach (IAA) has been implemented. Another innovative aspect of the methodology used has been to incorporate decoupling analysis between economic growth and environmental stress. This facilitates answering question iii). This is the first time that a comprehensive model is undertaken as described.
\end{abstract}

Keywords: Greenhouse gas emissions, Paris' Agreement, Ecuador, mitigation policies, LMDI-I model decomposition analysis, Innovative Accounting Approach. 


\section{MITIGATION AND ENERGY EFFICIENCY POLICIES IN ECUADOR}

\section{Introduction}

Despite its status as a Non-annex I country, an increased concern on Climate Change moved Ecuador (officially the Republic of Ecuador) to sign the Paris Agreement (2016). Ecuadorian authorities declared that it remains clear to Ecuador that the urgency of this phenomenon requires the widest possible global cooperation, in line with the norms, objective and principles of the United Nations Framework Convention on Climate Change (UNFCCC) (Gobierno Nacional de la República de Ecuador, 2015). Its National Contribution established that Ecuador intends to reduce its greenhouse gas (GHG) emissions in the energy sector to $20.4-25 \%$ below the Business as Usual (BAU) scenario. This scenario was defined through the Long-range Energy Alternatives Planning Systems software (LEAP). A potential for reducing emissions even further in the energy sector, to a level between 37.5 and $45.8 \%$ with respect to the BAU baseline, was also calculated.

In addition to mitigation commitments in GHG emissions, Ecuador's commitment under the Paris Agreement also includes a greater penetration of renewable energies sources (RES) in its energy matrix. This commitment arose from two government actions prior to the Paris Agreement titled National Plan of Good Living 2009-2013 and 2013-2017 (PNBV for its abbreviation in Spanish). According to PNBV 2009-2013, Ecuador aims to reach a 90\% of clean energy rate in its total electricity production in 2017 thanks to hydropower plants and increase the renewable energy percentage even more within the energy matrix by 2025 .

Together with mitigations and RES targets, a new constitution in 2008 launched "Good Living" as a crucial issue in its main legal text. "Good Living" is considered to be a societal paradigm based on the principle that economic growth on a planet with limited resources cannot be unlimited. Art. 283 of Ecuador's constitution says that the National Development Regime is established under the framework of an economic system that seeks to guarantee production and reproduction of the material and immaterial conditions that will facilitate "Good Living". This new vision references sustainable and harmonious management of nature to consider its limits and regeneration cycles. In other words, this implies decoupling environmental stress from economic growth.

Despite its contribution to total world $\mathrm{CO}_{2}$ equivalent emissions (hereafter $\mathrm{CO}_{2}$ ), which only represents $0.5 \%$ (Ministry of Environment, 2016), interest in Ecuador's case derives from the fact 
that the consequences of Climate Change would be especially serious given its geographical location. Jiménez et al. (2012) estimated that an increase in temperature would imply high losses for the agriculture sector in terms of crops. In the coastal region, floods would affect rice crops, corn and sugarcane. In general, around 80,000 hectares of rice would be lost, which represents 19\% of the cultivated surface nation-wide. Ecuador is highly concerned with Climate Change due to such consequences.

This article analyzes for the 2000-2014 period. i) What have the drivers of $\mathrm{CO}_{2}$ emission in Ecuador been? ii) What are the determining factors to be focused on with regards to energy policy efforts and the mitigation of GHG emissions? And iii) Is the economy of Ecuador moving towards decoupling between economic growth and environmental stress?

To answer questions i) and iii) an ex-post analysis was developed; to respond to question ii) an exante analysis was used. The analysis is a multi-sector type that focuses on energy transformation, industry, agriculture, transportation, construction, commerce and residential sectors. Ecuadorian authorities have considered all of these sectors as key, both for national actions as well as for their commitments with the Paris Agreement.

The research develops a comprehensive and innovative model based on three analyses. To the best of our knowledge, scientific literature offers no similar type of analysis, so this paper contributes to filling this gap. More specifically, to respond to question i) a decomposition analysis of the change in $\mathrm{CO}_{2}$ emissions has been developed using the LMDI-I model (Ang, 2004). The decomposing factors or effects used include Carbon Intensity, Renewable Energy Sources penetration, Energy Intensity, Economic Structure, Economic Activity and Population. Another novelty of this paper refers to its multisectoral approach, as it includes the residential sector together with productive sectors. To do that, the domestic sector incorporated into the National Accounts as the last one sector was considered to proxy the residential energy consumption. To answer question ii) this research implemented the so-called Innovative Accounting Approach, which includes Impulse Response Functions (IRFs) and the forecast error variance decomposition applied to the previously defined decomposition factors, according to Robaina-Alves and Moutinho (2013), Moutinho et al. (2016), and Cansino et al. (2018). Another innovative aspect of the methodology used has been to incorporate decoupling analysis between economic growth and environmental stress, measured by the volume of $\mathrm{CO}_{2}$ emissions. This facilitates answering 
question iii). For this, a decoupling index is calculated as of a second decomposition of the results obtained from the LMDI I analysis (Diakoulaki and Mandaraka, 2007; Jiang et al., 2016; Wang et al., 2016; Cansino and Moreno, 2017; Román-Collado et al., 2018a). The main methodological contribution lies in the fact that this is the first time that a comprehensive model is undertaken as described, which includes the LMDI, the IAA and the decoupling analyses. The study offers useful lessons for developing countries, and it could be used as a policy-making tool because it is easily transferable to any other time period or region.

This paper is structured as follows. After the Introduction, Section 2 explains Ecuador's main indicators and also offers a review of the literature. Section 3 describes the methods used. Data are presented in Section 4, with Section 5 showing and discussing the main findings. Conclusions and policy recommendations appear in Section 6.

\section{Ecuadorian context and literature review}

Ecuador is a South American country with a population of 16.38 million (The World Bank, 2018). Its economy is the eighth largest in Latin American while its annual growth average rate of constant GDP per capita was $2.57 \%$ between 2000 and 2016. In terms of human development, it has a score of 0.739 (UNDP, 2016) with $25.6 \%$ of its population living below the Poverty line (Central Intelligence Agency, 2017).

Ecuador's concern for Climate Change problems had moved its authorities to sign international agreements. In 1990, Ecuador signed the Vienna Convention (1985) and the Montreal Protocol (1987) to create environmental and GEI mitigation policies, as well as care for the ozone layer and climate change. In 1994, the country subscribed to the UN Framework Convention on Climate Change; in 1999, it signed the Kyoto Protocol, in 2000, it signed the Millennium Developments Goals and the Bali Action Plan in 2007. The 2008 Constitution also include, among other articles, concern for the preservation of the environment (mainly Article 414). The most recent commitment acquire has been to sign the Paris Agreement, which will come into effect in 2020, once the effectiveness of the Kyoto Protocol concludes.

In recent years, scholar's interest in Ecuador's $\mathrm{CO}_{2}$ emissions has produced emerging growing amount of scientific literature. Part of this literature shows controversy regarding the question of 
Environmental Kuznets Curve (EKC). For a list of countries, including Ecuador, Azomahou et al. (2005) using panel data researched the EKC using a nonparametric approach to model the relationship between greenhouse gas emissions and economic development. They found that that the relationship between GHG emissions and GDP displays a complex pattern, despite its monotonous shape, which is different from the well-known Kuznets curve obtained from ad hoc parametric specifications. This was in line with Rentería et al. (2016) that focuses specifically on the Ecuador case. However, Almeida (2013), Robalino-López et al. (2014b), ZambranoMonserrate et al. (2016), and Cuesta (2018) also focus on the Ecuador case; they gave support to the EKC hypothesis by finding that in the short-run, economic growth leads to more pollution, but in the long-run degradation begins to decrease. Other variables, such as energy consumption, help to explain the behavior of Pollutant emissions (in a similar sense see Román-Collado et al., 2018a). Based on the ECK approach Robalino-López et al. (2014a) conducted a model using a variation of the Kaya identity by taking 1980-2010 as the reference period to fix the parameters of the model. Energy efficiency has also been of concern in Ecuador, although from the mainly from an engineering perspective (Salazar and Panchi, 2014). Pollutant emissions from certain specific sectors also received attention from scholars, as was the cases of the electricity (Parra, 2015) and agriculture (Morocho, 2018) sectors. Finally, the constitutional concept of "Good Living" was analyzed in depth by Viteri (2015).

\section{Methodology}

\subsection{LMDI Analysis}

The comprehensive model developed starts by decomposing $\mathrm{CO}_{2}$ emission changes to find drivers and the inhibitors that influence them. Various and different decomposition techniques are found in the literature. Two recent reviews of the literature are offered in Cansino and Moreno (2017) and Román-Collado et al. (2018a).

Among the various IDA methods, the LMDI method seems to provide the most advantages (Ang, 2004; Timilsina and Shrestha, 2009; Zhang et al., 2009; Fernández-González et al., 2014; Guo et al., 2014; Chen and Yang, 2015; Shahiduzzaman and Layton, 2015; Sumabat et al., 2016). LMDII is a refined, non-parametric approach based on the IDA method, with a weighted logarithmic mean. 
The analysis conducted considers seven sectors for the Ecuadorian economy: energy, transportation, industry, agriculture, construction, commercial and residential. Following Cansino et al. (2015) and Cansino and Moreno (2017), six factors are proposed to analise the main drivers of the changes for total energy-related $\mathrm{CO}_{2}$ emissions in Ecuador from 2000 to 2014.

Decomposition factors include the Carbon Intensity effect (CI), Renewable Energy Sources share effect (RES), Energy Intensity effect (EI), Economic Structure effect (ES), Economic Activity ( $\left.\mathrm{Y}_{\mathrm{p}}\right)$ and Population effect $(\mathrm{P})$. The total $\mathrm{CO}_{2}$ emissions can be decomposed as:

$$
C O_{2}=\sum_{i=1}^{7} C I_{i} \cdot R E S_{i} \cdot E I_{i} \cdot E S_{i} \cdot \mathrm{EA} \cdot P=\sum_{i=1}^{7} \frac{C O_{2 i}}{F F_{i}} \cdot \frac{F F_{i}}{E_{i}} \cdot \frac{E_{i}}{Y_{i}} \cdot \frac{Y_{i}}{Y} \cdot \frac{Y}{P} \cdot P
$$

The subscript $i$ refers to a given sector from the seven ones considered. $\mathrm{CO}_{2 i}$ measures the energyrelated $\mathrm{CO}_{2}$ emissions of a given sector $i$. Similarly, $F F_{i}$ represents the total amount of fossil fuels use, $E_{i}$ stands for the energy consumption, and $Y_{i}$ measures the output of a given sector. Otherwise, $\mathrm{CO}_{2}$ and $Y$ variables without $i$ subscript represent the total $\mathrm{CO}_{2}$ emissions and the total output for the whole economy.

Variations in $\mathrm{CO}_{2}$ emissions may be evaluated by developing a multiplicative or additive decomposition methods. An additive LMDI-I approach is the one conducted in this paper. The overall ratio of variation in $\mathrm{CO}_{2}$ emissions between period 0 and $t$ may be decomposed as Eq [2] shows:

$$
\Delta C O_{2}=\mathrm{CO}_{2}-\mathrm{CO}_{2_{0}}=\Delta C I+\Delta R E S+\Delta E I+\Delta E S+\Delta E A+\Delta P
$$

$\Delta \mathrm{CO}_{2}$ measures changes in total $\mathrm{CO}_{2}$ emissions in the economy from one period to another, with the right-hand variables representing various contributing determinants as previously defined, but now being referred to as changes. By considering the additive decomposition identity, Eq [3] to [8] expose the LMDI formulas for each effect:

$$
\Delta C I=\sum_{i=1}^{7} w_{i}(t) \cdot \ln \left(\frac{C I_{i, t}}{C I_{i, 0}}\right)
$$




$$
\begin{aligned}
\Delta R E S & =\sum_{i=1}^{7} w_{i}(t) \cdot \ln \left(\frac{R E S_{i, t}}{R E S_{i, 0}}\right) \\
\Delta E I & =\sum_{i=1}^{7} w_{i}(t) \cdot \ln \left(\frac{E I_{i, t}}{E I_{i, 0}}\right) \\
\Delta E S & =\sum_{i=1}^{7} w_{i}(t) \cdot \ln \left(\frac{E S_{i, t}}{E S_{i, 0}}\right) \\
\Delta E A & =\sum_{i=1}^{7} w_{i}(t) \cdot \ln \left(\frac{E A_{t}}{E A_{0}}\right) \\
\Delta P & =\sum_{i=1}^{7} w_{i}(t) \cdot \ln \left(\frac{P_{t}}{P_{0}}\right)
\end{aligned}
$$

Using the mean value theorem the term $w_{i}(t)$ is the estimated weight to be applied from Eq [3] to Eq [8] and is defined by Ang (2005),

$$
w_{i}(t)=\frac{\mathrm{CO}_{2_{i, t}}-\mathrm{CO}_{2,0}}{\ln C O_{2, t}-\ln C O_{2 i, 0}}
$$

According to the nomenclature used, Eq [3] to Eq [8] captures changes in every given sector during periods $t$ and 0 .

Eq [3] measures the Carbon Intensity factor ( $\mathrm{CI})$, and $\Delta C I$ captures changes in $\mathrm{CO}_{2}$ emissions from fossil fuel consumption $\left(=\mathrm{CO}_{2 i} / F F_{i}\right)$. The $\mathrm{CI}$ factor describes the $\mathrm{CO}_{2}$ emission amount produced by each sector with respect to the consumption of fossil fuels. It serves as an energy mix factor allowing to analise the substitution between fossil fuel types. This is possible if the statistics show changes in the types of primary energy sources used (i.e., natural gas replacing coal or vice versa). It is assumed that the higher the quality of a fossil fuel, the less $\mathrm{CO}_{2}$ pollutant is.

Eq [4] shows the Renewable Energy Source share factor (RES), and $\triangle R E S$ indicates the share of fossil fuel consumption with respect to the total primary energy consumed ( $\left.=F F_{i} / E_{i}\right)$ (O'Mahony, 2013; Cansino et al., 2018). 
Eq [5] measures the Energy Intensity factor (EI), and $\Delta E I$ captures the total primary energy required in comparison to the output of the considered sector $\left(=E_{i} / Y_{i}\right)$. The EI factor is used as a proxy of the energy efficiency of a country's economy (Goldemberg and Johansson, 2004; Voigt et al., 2014).

Eq [6] presents the Economic Structure factor (ES), and $\Delta E S$ captures the effect of structural changes in Ecuador's economy. It incorporates the relative impact of structural changes on Ecuador's economy in terms of $\mathrm{CO}_{2}$ emissions for a given year under analysis.

Eq [7] is the Economic Activity (EA), and $\triangle E A$ measures the output per capita between two periods. The EA factor captures the income factor in $\mathrm{CO}_{2}$ emission variations from energy consumption.

Eq [8] shows the Population factor $(\mathrm{P})$, and $\Delta P$ indicates the variation of total population between given periods. The $\mathrm{P}$ factor enables the effects of population growth to be analyzed as an explain factor for $\mathrm{CO}_{2}$ emissions.

In order to accommodate cases of zero value, Ang and Liu (2001) and proposed that the best way to handle this situation is by substituting zeros for a $\delta$ value between $10^{-10}$ and $10^{-20}$ (see also Ang and Choi, 1997; and Ang et al., 1998).

\subsection{IAA}

IAA is the second analysis in the comprehensive model implemented here. It facilitates the relationships between $\mathrm{CO}_{2}$ emission drivers and identifies how they could influence each other in the future (Robaina-Alves and Moutinho, 2013; Moutinho et al., 2016). Both short-run and longrun relationships are explored. IAA includes Impulse Response Functions (IRFs) and forecast error variance decomposition (Maghyereh, 2004; Cansino et al., 2018). One of the advantages of the IAA method over other approaches used in the literature is that it allows us to incorporate a forward period analysis, i.e. perform predictions of the behavioral relationships between time series from the selected sample period (Park and Ratti, 2008; Ozkan and Ozkan, 2012; Shahbaz et al., 2013). In this research, the generalized forecast variance decomposition approach estimates simultaneous shock effects, which are determined from the estimation of the VAR model to test the strength of casual relationships between the determining factors of total $\mathrm{CO}_{2}$ emissions. 


\subsection{Decoupling analysis}

Decoupling analysis may be addressed by using the Tapio (2005) decoupling index. However, this type of elasticity index only gives a rough measure of decoupling status between environmental stress and economic growth for a specific economic area (Román-Collado et al., 2018a). For countries like Ecuador, where some type of decoupling is required even at a constitutional level, there is a high interest in properly measuring its decoupling status as efforts are made to reach it. Here, the effort is conceived as a general term referring to any type of actions that might directly or indirectly induce a decrease in $\mathrm{CO}_{2}$ emissions, independently of energy changes due to the economic activity. In this sense, the term 'effort' includes the use of less pollutant fuels, energy efficiency enhancing measures, shifts towards less energy intensive activities, as well as changing consumption patterns to more suitable ones among the population.

As of [2], it is possible to determine the contribution of each decomposition factor per sector in the decoupling status between the change in economic growth and $\mathrm{CO}_{2}$ emissions in Ecuador. To understand the effort carried by the decomposition factors for each of the sectors analyzed, it is possible to perform a second decomposition based on the results of the first decomposition. This second decomposition allows decoupling index to be calculated, and one that is more sophisticated than the Tapio Index (Diakoulaki and Mandaraka, 2007; UNEP, 2011). A decoupling oriented effort is conceived as referring to any type of action that directly or indirectly might induce i) a decrease in carbonization; ii) in energy intensity; iii) the promotion of an economic structure change towards less energy intensive sectors; iv) the promotion of RES use v) consumption patterns that are environmental friendly (Jiang et al., 2016; Cansino and Moreno, 2017; Wang et al., 2016). Following Cansino and Moreno (2017) and Román-Collado et al. (2018a) to define the second decoupling index, it is presumed that economic growth sparks a higher level of $\mathrm{CO}_{2}$ emissions. As of [2], the decoupling effort in absolute terms or the inhibitor effect of sector $i$-ith $\left(\Delta E E_{i}\right)$ is defined as the difference between the change in the level of $\mathrm{CO}_{2}$ emissions and the effect of economic activity. In [10], the efforts undertaken in Ecuador to achieve decoupling are summarized in the $\Delta E E_{t}$ effect. This effect shows that $\mathrm{CO}_{2}$ emission changes are only attributed to the carbonization, RES penetration, energy intensity, structural and population effects, excluding those provoked by the activity effect. Similarly to Jiang et al. (2016), by reordering Eq [2], the $\Delta E E_{t}$ effect is defined as follows: 


$$
\Delta E E_{t}=\Delta C O_{2}-\Delta E A=\Delta C I+\Delta R E S+\Delta E I+\Delta E S+\Delta P
$$

A negative value of the $\Delta E E_{t}$ effect might occur because of a positive change in $\mathrm{CO}_{2}$ emissions, with $\triangle \mathrm{CO}_{2}$ being offset by the $\mathrm{CO}_{2}$ emission change due to the activity effect. Therefore, a negative value of the $\Delta E E_{t}$ effect does not necessary lead to a negative value of the total $\mathrm{CO}_{2}$ emission change $\Delta E^{T}$ (Jiang et al., 2016).

Hence, to assess the degree to which the aforementioned efforts are effective in decoupling $\mathrm{CO}_{2}$ emissions variations from economic growth, the decoupling index $\gamma_{i}$ is calculated in Eq [11]. This decoupling index shows the changes in $\mathrm{CO}_{2}$ emissions in terms of the activity effect. The decoupling index $\gamma_{i}$, calculates the contribution of all other effects in the decoupling process between the periods $t$ y $t-1$.

$$
\begin{gathered}
\gamma_{\text {TOTAL }}^{i}=-\frac{\Delta E E_{i}}{\Delta E A^{i}}=-\frac{\Delta C I^{i}}{\Delta E A^{i}}-\frac{\Delta P^{i}}{\Delta E A^{i}}-\frac{\Delta E S^{i}}{\Delta E A^{i}}-\frac{\Delta E I^{i}}{\Delta E A^{i}}-\frac{\Delta R E S^{i}}{\Delta E A^{i}} \\
=\gamma_{C I}^{i}+\gamma_{P}^{i}+\gamma_{E S}^{i}+\gamma_{E I}^{i}+\gamma_{R E S}^{i}
\end{gathered}
$$

When negative economic growth leads to a reduction in $\mathrm{CO}_{2}$ emission levels, Diakoulaki and Mandaraka (2007) consider a negative activity effect. In this case, the decoupling index $\gamma_{i}$ is defined as the effort to reduce the level of $\mathrm{CO}_{2}$ emissions beyond those attributable to the negative activity effect and is defined as stated in Eq [12]:

$$
\begin{gathered}
\gamma_{\text {TOTAL }}^{i}=\frac{\Delta E E_{i}-\Delta E A^{i}}{\Delta E A^{i}}=\frac{\left(\Delta C I^{i}+\Delta P^{i}+\Delta E S^{i}+\Delta E I^{i}+\Delta R E S^{i}\right)-\Delta Y_{P}^{i}}{\Delta E A^{i}} \\
\gamma_{\text {TOTAL }}^{i}=\frac{\Delta C I^{i}}{\Delta E A^{i}}+\frac{\Delta P^{i}}{\Delta E A^{i}}+\frac{\Delta E S^{i}}{\Delta E A^{i}}+\frac{\Delta E I^{i}}{\Delta E A^{i}}+\frac{\Delta R E S^{i}}{\Delta E A^{i}}-\frac{\Delta A^{i}}{\Delta E A^{i}} \\
=\gamma_{C I}^{i}+\gamma_{P}^{i}+\gamma_{E S}^{i}+\gamma_{E I}^{i}+\gamma_{R E S}^{i}-1
\end{gathered}
$$

In the case of Eq [11] and [13], $\gamma_{\text {TOTAL }}^{i}$ corresponds to the total decoupling index of each sector while $\gamma_{C I}^{i}, \gamma_{P}^{i}, \gamma_{E S}^{i}, \gamma_{E I}^{i}$ and $\gamma_{R E S}^{i}$ correspond to partial decoupling indexes associated with the effects of carbonization, population, structure, energy intensity and energy mix respectively. 
In both cases, if the index value is $\gamma_{\mathrm{i}} \geq 1$, it denotes strong decoupling efforts. If the decoupling index is between $0<\gamma_{i}<1$, it denotes weak decoupling efforts. Finally, if the decoupling index is $\gamma_{i} \leq 0$, it denotes that there has been no decoupling effort (Diakoulaki and Mandaraka, 2007; Jiang et al., 2016).

In keeping with Roinioti and Koroneos (2017), values greater than zero for $\gamma_{C I}^{i}, \gamma_{P}^{i}, \gamma_{E S}^{i}, \gamma_{E I}^{i}$ and $\gamma_{R E S}^{i}$ mean that they have an inhibiting effect on sectorial emission of $\mathrm{CO}_{2}$, thus contributing to decoupling on economic growth.

\section{Data}

The data used in the work comes from the National Energy Balance drafted jointly by the Ministerio Coordinador de Sectores Estratégicos (Ministry for the Coordination of Strategic Sectors), Ministerio de Electricidad y Energía Renovable (Ministry for Electricity and Renewable Energy) and the Ministerio de Hidrocarburos (Ministry for Fossil Fuels) together with their assigned institutions. At the time when this research concluded, the latest report provided data up until 2014. Its historic series, covering between 2000 and 2014, constitutes the sole bases with indepth information to respond the research questions presented herein. The balance provides information regarding energy consumption and greenhouse gas emissions in Ecuador. Moreover, it details energy flows based on energy sources (primary and secondary) by means of production chains, transformation, distribution and energy consumption. The Energy Balance includes seven sectors: energy transformation or the energy sector, industry, agriculture, transportation, commerce and residential sectors.

The methodology used to draft the Energy Balance corresponds to the dictates of the Latin American Energy Organization (abbreviated as OLADE from the Spanish name Organización Latinoamericana de Energía). In the Balance, energy is measured in the Barrels of Oil Equivalent (BOE) and emissions in kilotons (kton) of $\mathrm{CO}_{2}$ equivalent. To calculate GHG, the Intergovernmental Panel on Climate Change (IPCC) methodology was used. In terms of the energy demand, non-energy usage of these sources were excluded, which corresponds to fossil fuels used to manufacture lubricants, mineral turpentine, spray oil, and rubber solvent, among others. 
Greenhouse gas emissions for the energy sector were recorded as the total emissions registered in each of the phases of the energy flow chain: offer, transformation and own use. Emissions of primary energy flows are entirely allocated to the energy sector avoiding double counting.

Ecuador's GDP statistics were taken from the Central Bank of Ecuador and correspond to a series of constant prices with the base year as 2007. GDP is measured in thousands of millions of dollars and its 18 economic sectors were grouped in the same seven sectors as presented by the Energy Balance. The energy sector was considered as the total GDP for the crude oil and mining sectors, oil refining and the supply of electricity and water. To analyze the role of homes in $\mathrm{CO}_{2}$ emissions, the domestic service sector in private homes for National Accounting as the proxy for the size of this sector. Finally, population data was obtained from the World Bank.

\section{Main results}

\subsection{LMDI results}

Figure 1 shows the behavior of $\mathrm{CO}_{2}$ emissions and the contributions of the six decomposition factors during the 2001-2004 period. Figure A.1 in the annex provides an analytical break down by sectors.

(Figure 1) 


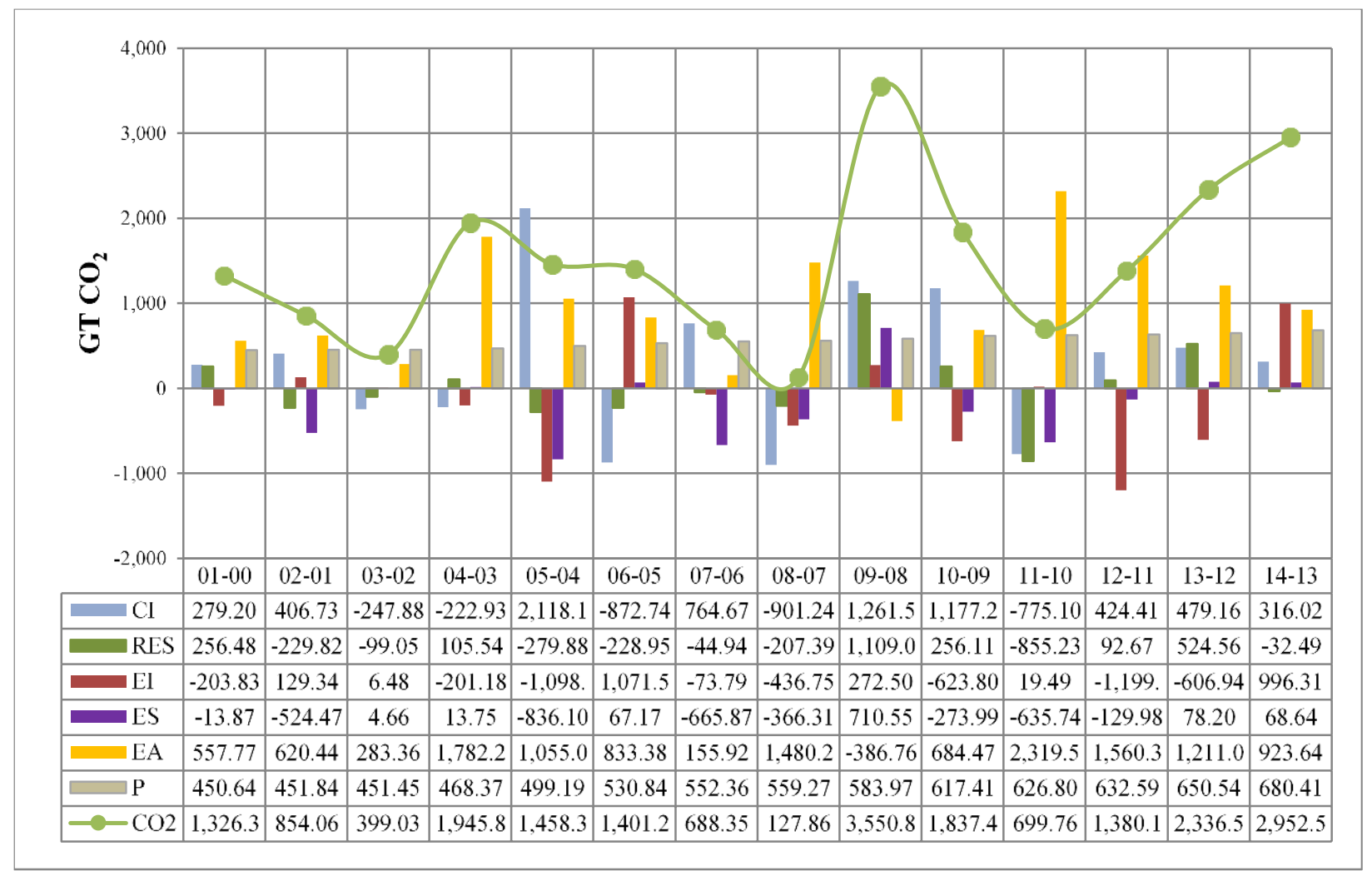

Figure 1. Main figures for factors considered in LMDI analysis 2000-2014.

Source: Own elaboration.

The main drivers that explain the changes in Ecuador's $\mathrm{CO}_{2}$ emissions were carbon intensity (CI), population and economic activity effect. This latter warns about the existence of an economic model in which $\mathrm{CO}_{2}$ emissions are coupled to economic growth. The importance of the CI effect as a driver of $\mathrm{CO}_{2}$ emissions was especially important between the years 2005 and 2011. The population effect behaved as expected, acting as a driver of GHG emissions.

In terms of sectors, the CI factor is highly linked to emissions from the energy sector. All other sectors worked as inhibitors of the CI effect, although with a lesser magnitude and solely for the 2001 to 2007 period. Therefore, the energy sector leads the carbon intensity behavior as a driver of emissions. These results are coherent with an intensive energy mix when fossil fuels are used and this is in line with the findings of Salazar and Panchi (2014). These authors pointed out that in the 1999-2005 period, the growth rate of RES was almost null and from 2006 to 2011 there was a growth rate of only $4.6 \%$. Nevertheless, the plants using fossil fuels, especially the coal-fired power 
plants, grew $16.4 \%$ between 2005 and 2011. Specifically, natural gas-fired power plants grew 16\% in 2008-2009.

To understand the importance of the energy sector, one must remember that in 2003, a pipeline managed by the firm OCP Ecuador Ltd. Co. began operations. This facilitated an increase in the extraction of crude oil. Along this same line, and due to drought in 2005, the greatest generation of electricity from hydraulic sources decreased. This decrease in hydro electrical power was compensated by fossil fuel-fired thermal plants. This explains why in 2010 Ecuador registered the highest $\mathrm{CO}_{2}$ emission factor in the generation of electricity with-397.5 $\mathrm{g} \mathrm{CO}_{2} / \mathrm{kWh}$ - (well above that $241 \mathrm{~g} \mathrm{CO}_{2} / \mathrm{kWh}$ value registered for the 2001-2014 period) (Parra, 2015). This sector's behavior improved as of 2011 due to the closure of several oil wells.

The second decomposition factor used (RES) exemplifies the impact of renewable energies in GHG emissions. Despite the fact that the RES factor had a lesser impact, Figure 1 shows that it behaved as an inhibitor, except for the years 2007-2008.

From the sector, the energy sector influenced the behavior of this factor to a greater extent, followed by the industrial sector. The influence of the sector gained momentum in 2005 due to the increased contribution of hydro electrical power. On the other hand, the residential sector began to show its weight in the behavior of the RES factor, as indicated in Figure 2.

(Figure 2) 


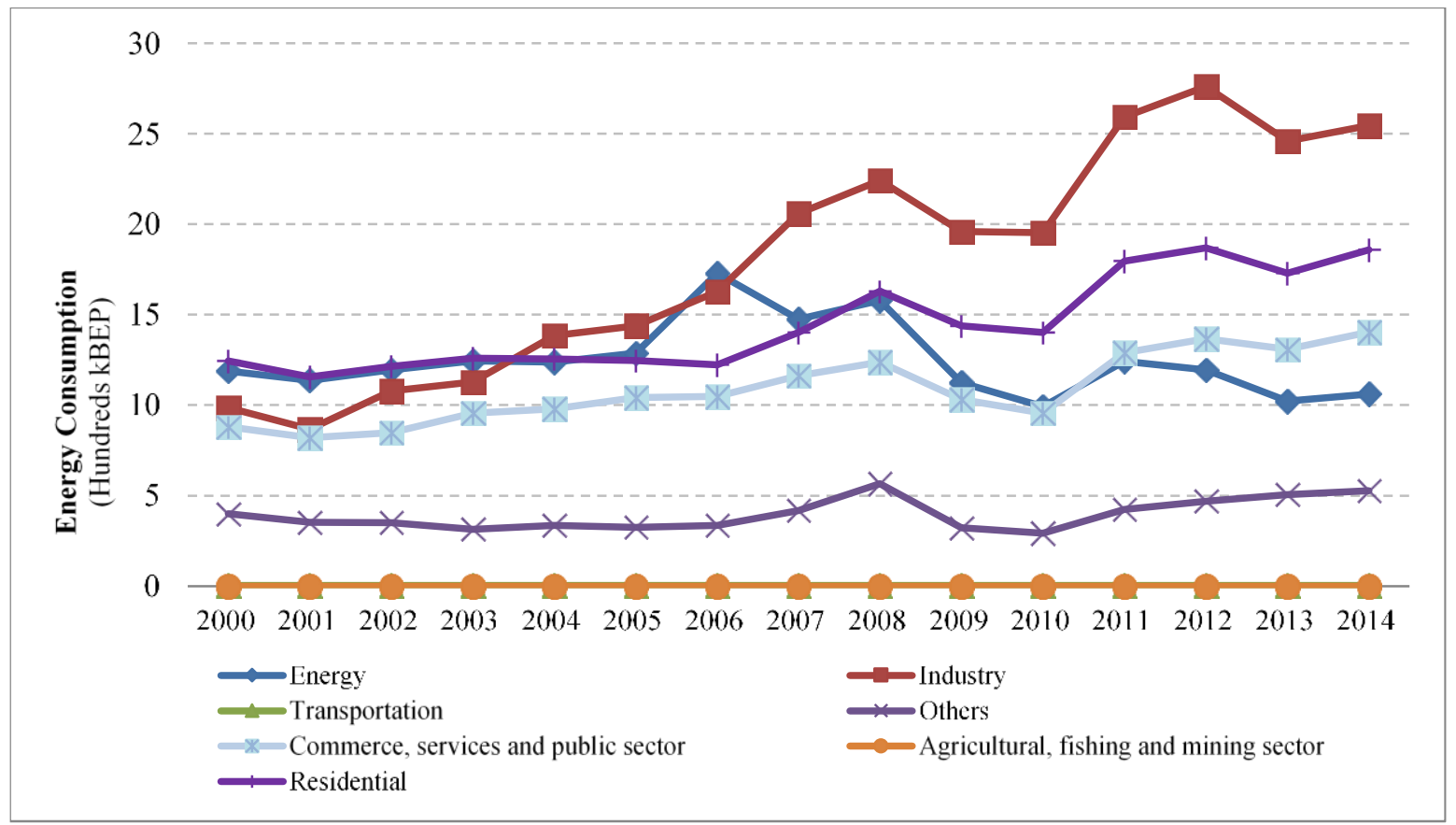

Figure 2. Energy consumption of non-fossil source by economic sector 2000-2014.

Source: Own elaboration.

The use of renewable energies on behalf of the industrial and residential sectors has advanced at an accelerated rate. However, in 2009 and 2010 and due to a recession in the country both the residential and industrial sectors showed a decrease in the demand for renewable energy. The rapid penetration of RES in Ecuador's energy matrix could benefit from the introduction of tender mechanisms for new generation plants. Other Latin American countries have been successful in this regard, but Ecuador has yet to use this option (International Renewable Energy Agency, 2015). The EI factor worked as an inhibitor of $\mathrm{CO}_{2}$ emissions, but without compensating the drivers. The greatest inhibiting effect was seen in 2005, 2006 and 2012. In 2005 and 2006 registered sharp increases in crude oil prices. Based on sectors, the exceptions appeared in the transportation sector for 2002-2004 period and for 2007, the industrial sector in 2006 and the commercial sector in 2007. For these sectors, one must analyze the existence of a possible knock-off effect associated with technological improvements. (Somuncu and Hannum, 2018). The contribution of the industrial sector in the mitigation of greenhouse gases coincided with technological improvements, in addition to the implementation of clean technology. These results recommend acting on the energy intensity of the transportation, industrial and commercial sectors. In the transportation sector, 
together with standard recommendations to favor public transportation, efforts must be made to increase the use of electrified railways to transport goods, if and when the electricity matrix increases the participation of clean energy generation technologies (Wilmsmeier and Guidry, 2013). Together with this, the rapid develop of the e-commerce currently forces society to deal with the last mile problem of logistic (Gevaers et al., 2011). The industrial sector could receive fiscal benefits for company tax linked to the investment in technologies that improve efficiency or those focusing on the sequestration of polluting emissions (Román-Collado et al., 2018b). Likewise, the commercial sector could improve its efficiency through investments that improve the insulations of large malls. In this regard, a higher standard demand for Ecuador's Building CodeNEC-11—would be recommendable (Comité Ejecutivo de la Norma Ecuatoriana de la Construcción, 2011).

When it comes to the behavior of the ES factor, the reduced importance of the transportation sector in Ecuador's economic structure in 2004 and 2005 influenced in the contribution of the ES factor in the reduction of GEI emissions. In 2009 and 2014, this sector saw an upturn in its contribution to the increase of GHG emissions. On the other hand, the greater weight of the energy sector as a driver of emissions from 2004 until 2008 is due to a constant increase in international oil prices.

Also, the EA factor contributed positively to the variations of GEI emissions during the period studied. The exception was 2009. That year, Ecuador saw an economic slowdown due to the price of international oil prices. The transportation sector was determining sector in the behavior of EA, followed by the energy and industrial sectors.

P effect drove GHG emissions as was expected, in line with Robalino-López et al. (2014a). These authors denoted that the extreme poverty rate in Ecuador declined significantly between 2000 and 2010. In 2000, the estimate was approximately $20.7 \%$ of the population; by 2010 , this number had dropped to $4.6 \%$ of the total population. This is largely explained by emigration and the economic stability achieved after the dollarization of the economy. Transportation is the most important sector. Naciph et al. (2013) offered limited yet interesting information about $\mathrm{CO}_{2}$ emissions for transport in terms of student use. Contrary to industrialized countries where the residential sector is more important than transportation, in Ecuador, this sector has a greater specific weight in the country's economy. In this context, new technologies facilitating car-sharing are a very costeffective way to optimize the use of passenger cars more efficiently, thus reducing its importance 
as a driver of emissions (Schor, 2016). Along this same line would be the installation of selfsufficient energy systems in homes by incorporating small, clean technology devices. Chile's experience with the Netbilling Act is a precedent to be taken into consideration (Walters et al., 2018).

\subsection{IAA results}

To ensure robustness before estimating the VAR model, statistical properties of CI, EI, EA, ES, RES and P effects are analised. Table A.1 in the annex shows that the mean, variance, and autocorrelation of the time series for the VAR model all remained constant over time (Brooks, 2014). For CI, EI, EA, ES and RES effects means and variances did not show tendency. ADF's test showed that was no autocorrelation between these effects, nor was there any autocorrelation (see supplemental material). Due to its nature, only the Population effects revealed a tendency, but the unit root test showed all effects were stationary in the first differences. Engel-Granger's test determined that the series were not co-integrated ( $\mathrm{p}$ value $>0.05$ ).

\subsubsection{Results from variance decomposition}

Table 1 presents the results obtained for the generalized variance decomposition over the selected timespan. This research considered a ten-year period for the decomposition factor of $\mathrm{CO}_{2}$ emissions in Ecuador. The variance decomposition shows how much the predicted error variance of a variable is described by innovation generated from each independent variable in the system.

(Table 1) 
Table 1. Variance decomposition

\begin{tabular}{|c|c|c|c|c|c|c|}
\hline Period & CI & RES & EI & ES & EA & $\mathbf{P}$ \\
\hline \multicolumn{7}{|c|}{ Variance decomposition of CI: } \\
\hline 1 & 100.0000 & 0.000000 & 0.000000 & 0.000000 & 0.000000 & 0.000000 \\
\hline 2 & 57.38620 & 2.346447 & 3.029810 & 17.63667 & 19.50927 & 0.091596 \\
\hline 3 & 29.49275 & 6.046937 & 33.41920 & 7.024960 & 23.95696 & 0.059191 \\
\hline 4 & 30.20455 & 3.895387 & 45.27266 & 4.410487 & 16.18440 & 0.032515 \\
\hline 5 & 33.70266 & 3.486255 & 44.08101 & 4.225269 & 14.47502 & 0.029789 \\
\hline 10 & 33.14091 & 3.560160 & 44.51605 & 4.318444 & 14.43465 & 0.029787 \\
\hline \multicolumn{7}{|c|}{ Variance decomposition of RES: } \\
\hline 1 & 64.02666 & 35.97334 & 0.000000 & 0.000000 & 0.000000 & 0.000000 \\
\hline 2 & 53.11551 & 29.87786 & 14.95493 & 0.022541 & 2.020738 & 0.008417 \\
\hline 3 & 48.75352 & 26.01929 & 19.25088 & 2.801488 & 3.133468 & 0.041351 \\
\hline 4 & 41.88260 & 23.35987 & 25.59112 & 2.386764 & 6.744384 & 0.035263 \\
\hline 5 & 40.53572 & 19.73968 & 30.85341 & 2.869476 & 5.969984 & 0.031734 \\
\hline 10 & 39.44256 & 18.63762 & 32.43613 & 3.126156 & 6.302104 & 0.055429 \\
\hline \multicolumn{7}{|c|}{ Variance decomposition of EI: } \\
\hline 1 & 11.93017 & 36.72795 & 51.34188 & 0.000000 & 0.000000 & 0.000000 \\
\hline 2 & 16.62990 & 33.33257 & 46.52960 & 2.977543 & 0.529190 & 0.001197 \\
\hline 3 & 17.43661 & 33.06219 & 45.38558 & 3.179245 & 0.928847 & 0.007524 \\
\hline 4 & 17.77026 & 31.56806 & 45.17881 & 3.287832 & 2.187978 & 0.007056 \\
\hline 5 & 18.97435 & 29.77726 & 45.63968 & 3.066387 & 2.531427 & 0.010895 \\
\hline 10 & 20.23564 & 28.37164 & 45.44579 & 2.955266 & 2.968940 & 0.022718 \\
\hline \multicolumn{7}{|c|}{ Variance decomposition of ES: } \\
\hline 1 & 18.17109 & 67.02400 & 0.884735 & 13.92018 & 0.000000 & 0.000000 \\
\hline 2 & 13.75404 & 51.50229 & 20.49325 & 10.92481 & 3.313246 & 0.012364 \\
\hline 3 & 16.72425 & 40.66796 & 31.38117 & 8.548324 & 2.661188 & 0.017114 \\
\hline 4 & 18.10400 & 39.72336 & 30.66016 & 8.352205 & 3.143511 & 0.016772 \\
\hline 5 & 17.89781 & 38.70524 & 31.64612 & 8.651017 & 3.082004 & 0.017800 \\
\hline 10 & 18.10873 & 36.75547 & 32.97450 & 8.453027 & 3.673565 & 0.034709 \\
\hline \multicolumn{7}{|c|}{ Variance decomposition of EA: } \\
\hline 1 & 23.78321 & 51.30177 & 12.41278 & 4.159627 & 8.342609 & 0.000000 \\
\hline 2 & 23.35713 & 49.28957 & 12.29949 & 6.319887 & 8.701182 & 0.032742 \\
\hline 3 & 22.68233 & 45.76119 & 12.88360 & 6.109912 & 12.53135 & 0.031612 \\
\hline 4 & 23.82239 & 40.49266 & 17.77261 & 6.099312 & 11.76722 & 0.045810 \\
\hline 5 & 24.57900 & 39.24837 & 18.55520 & 5.942549 & 11.61530 & 0.059575 \\
\hline 10 & 24.94073 & 38.11436 & 18.90702 & 6.062296 & 11.84354 & 0.132051 \\
\hline \multicolumn{7}{|c|}{ Variance decomposition of $P$ : } \\
\hline 1 & 22.31505 & 4.400698 & 30.37099 & 1.024324 & 29.82865 & 12.06029 \\
\hline 2 & 26.23396 & 5.887627 & 18.33133 & 9.054020 & 31.28317 & 9.209888 \\
\hline 3 & 32.19301 & 4.045198 & 11.56641 & 13.62564 & 29.79309 & 8.776658 \\
\hline 4 & 32.40513 & 3.339482 & 9.180209 & 15.75755 & 29.99985 & 9.317778 \\
\hline 5 & 31.25042 & 2.937308 & 8.406543 & 16.47756 & 31.57339 & 9.354781 \\
\hline 10 & 32.48718 & 1.935758 & 4.314652 & 19.76073 & 32.20638 & 9.295307 \\
\hline
\end{tabular}

The results indicate that $33.14 \%$ of the CI effect is due to its own innovative shocks. The standard deviation shock in the EI factor is the variable that better explains carbon intensity with a 
percentage of $44.51 \%$. Other factors that explain the CI are the EA and ES effects with $14.43 \%$ and $4.31 \%$, respectively. The RES factor only explains carbon intensity with a $3.56 \%$.

A portion of $18.63 \%$ of RES effect may be explained by its own innovative shock. However, a strong share of this effect is explained by CI (39.44\%) and by EI effect (32.43\%). The EA, ES, and P factors only explain RES with a $6.30 \%, 3.12 \%$ and a $0.05 \%$, respectively.

The empirical evidence indicates that $45.44 \%$ of the EI effect is due to its own innovative shocks. RES and CI effects also explain a strong percentage of this effect--28.37\% and 23.23\% respectively-while EA and ES explain it almost in the same portion (2.96\%) and P only give explanation to $0.02 \%$.

The structural composition of Ecuador's economy is mainly affected by the RES share effect (36.75\%) and the EI effect (32.97\%). The ES factor is explained solely by its own innovative shock with a small portion as $8.45 \%$.

This small portion of the EA factor is explained by its own shocks (11.84\%), while the contribution of the RES factor is the main calculation $(38.11 \%)$ is followed by CI (24.94\%) and EI (18.90\%) factors. The economic structure effect is $6.06 \%$ while the Population factor explained only $0.13 \%$. Similar to the case of the EA factor is the population effect, which is explained by its own standard innovative shock with a portion of $9.29 \%$. The standard deviation shock in the CI penetration effect and EA effect represented the higher proportion with a $32.48 \%$ and a $32.20 \%$ respectively. The value for ES was $19.76 \%$. Finally, EI (4.31\%) and RES (1.93) explained the lower portion.

Taking 5\% as a threshold, it could be inferred that there is bidirectional causality between the carbon intensity and the Energy Intensity effect. This means that technological advanced energy efficiency orientation represents an effective way to reduce $\mathrm{CO}_{2}$ emissions in Ecuador. Bidirectional causality also appears between RES and EI. Thus, by considering the reference of $5 \%$, we may infer that there is unidirectional causality from CI to RES, EA and P, from RES to ES and EA, from EI to ES and from EA to P.

Following Cansino et al. (2018), the results obtained as shown in Table 1 highlight the following major findings:

If the Energy Intensity effect decreases, then the CI decreases too because the energy requirements to obtain an additional unit of output are lower; therefore, total energy related emissions decrease. 
If the RES effect decreases, the EI also decreases, due to most RES use advanced techniques and resources such as the sun or wind, which are freely accessed.

If the EA effect decreases, the Population effect also decreases. The main reason behind this is the income effect on family consumption patterns.

The ES effect and EA effect cause the RES effect. Moreover, a unidirectional causality exists from $\mathrm{P}$ effect to CI effect.

\subsubsection{Impulse-Response analysis}

Impulse-Response Functions (IRF) allows us to simulate the decomposition effects involved in the analysis over time. Figure 3 represents the IRFs for the six effects used in the LMDI decomposition analysis accomplished. This Figure shows that carbon intensity in the short term reacts more significantly to shocks in EA and the Energy Intensity effect, compared to shocks in other effects. The reaction to EA has an opposite behavior to shocks in EI. Nevertheless, both of reactions end up dissipating in the long-run.

The RES share effect has a significant reaction to a shock in the CI factor, in the EA effect and to a shock in itself. The three reactions have the same behavior until they reach the $3^{\text {rd }}$ time horizon; after this point, the EA effect turns to the opposite behavior. The three reactions dissipate after the $6^{\text {th }}$ time horizon. The response to shocks decreases in the long-run.

EI reacts more sharply to shocks in RES, EA and CI. The first two have the same behavior, but the last shows the opposite reaction. However, the response to shock disappears rapidly after the $2^{\text {nd }}$ time horizon to dissipate in the long-run (after the $8^{\text {th }}$ time horizon).

The economy structure effect reacts to all effects except to Population. ES effect reacts less sharply after the $5^{\text {th }}$ time horizon. Finally, the response to these shocks disappears in the long term in a similar way as EI.

When analyzing the Economic Activity effect, the sharpest reactions come from shocks in RES, CI and itself (three reactions showed a similar behavior) and also in EI (but with an opposite behavior). The response to shocks dissipates after $6^{\text {th }}$ time horizon. 
Finally, the Population effect reacts to all effects except to itself. Reaction patterns are not dissimilar in trends and responses do not disappear in the long-run.

Most of the factors have a significant reaction to a shock in the Economic Activity, RES and the Carbon Intensity effect. These results would seem to indicate coupling between $\mathrm{CO}_{2}$ emissions and economic growth. IRF results also show the importance of mix level resource efficiency to mitigate $\mathrm{CO}_{2}$ emissions without compromising economic growth.

(Figure 3) 
Response of $G$ to Cholesky

One SD. monorations

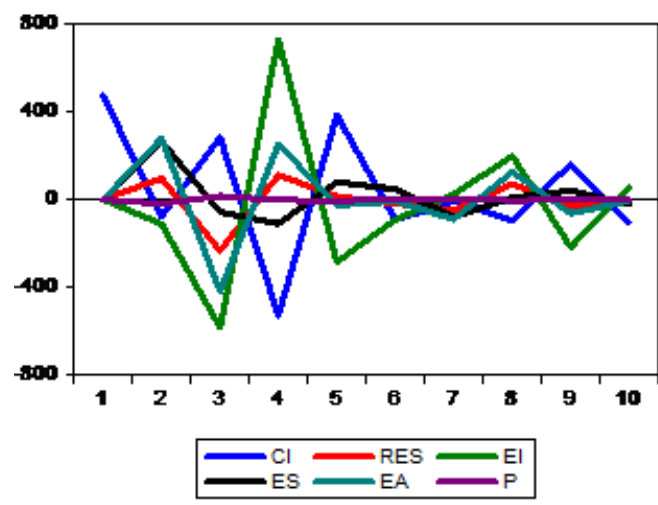

Response of $\mathrm{B}$ to Gonosky One SD. mnovalions

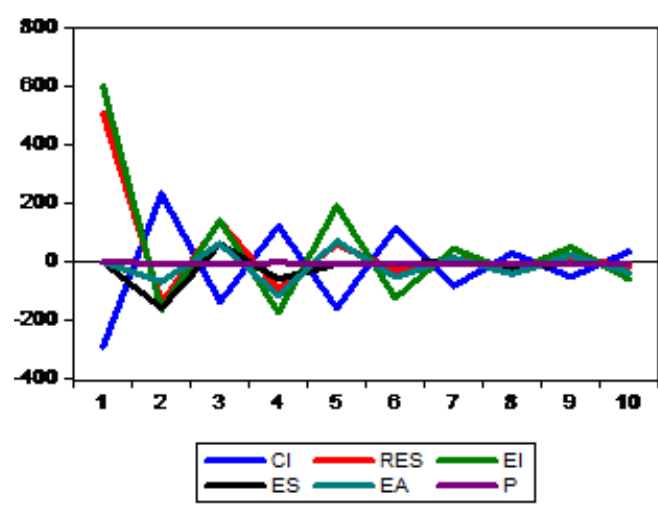

Response of EA to Gonesky One SD. mowations

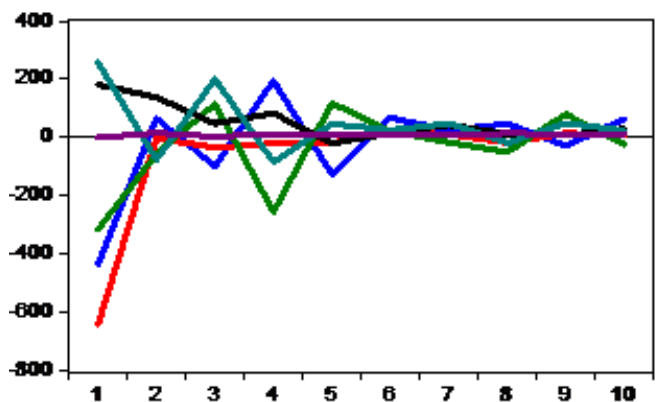

Response of RES to Gonosky

One SD. hnowetions

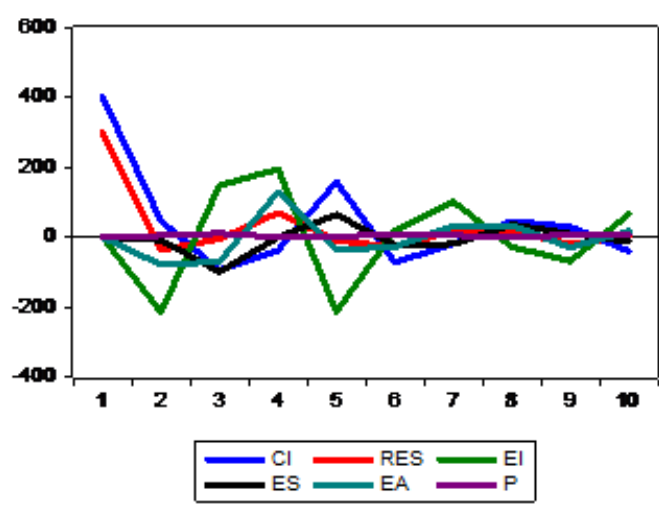

Response of ES to Cholesty One SD. mnowetions

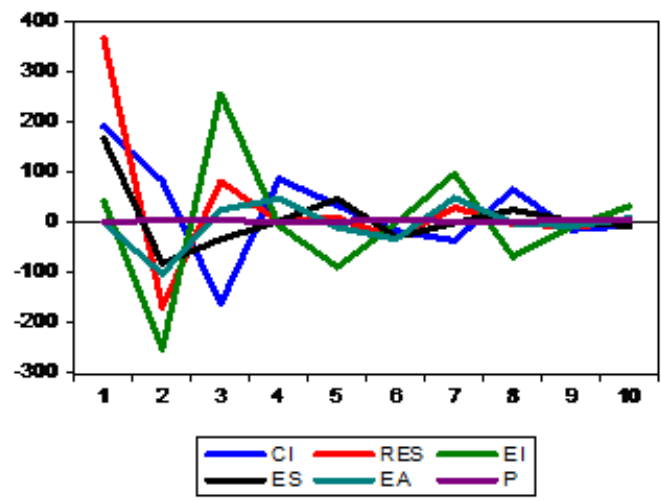

Response of P to Cholesky One SD. mowations

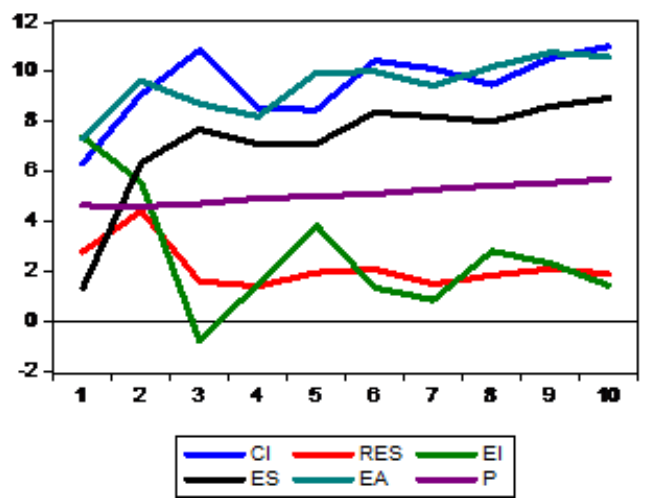

Figure 3. Impulse-Response functions.

Source: Own elaboration. 


\subsection{Decomposition index results}

The decoupling index, calculated according to Eq [11] and [13], determines the degree to which the $\mathrm{CO}_{2}$ emission reduction effort outweighs the activity effect in Ecuador from 2000 to 2014. This gives a measure (finer than the Tapio index) of the real progress in decoupling economic growth from environmental stress measured as $\mathrm{CO}_{2}$ emissions. It should be borne in mind that this is a requirement included in Ecuador's 2008 Constitution.

Figure 4 shows the trend of the decoupling, broken down into the five considered effects, all of which have been included in the LMDI analysis.

(Figure 4)

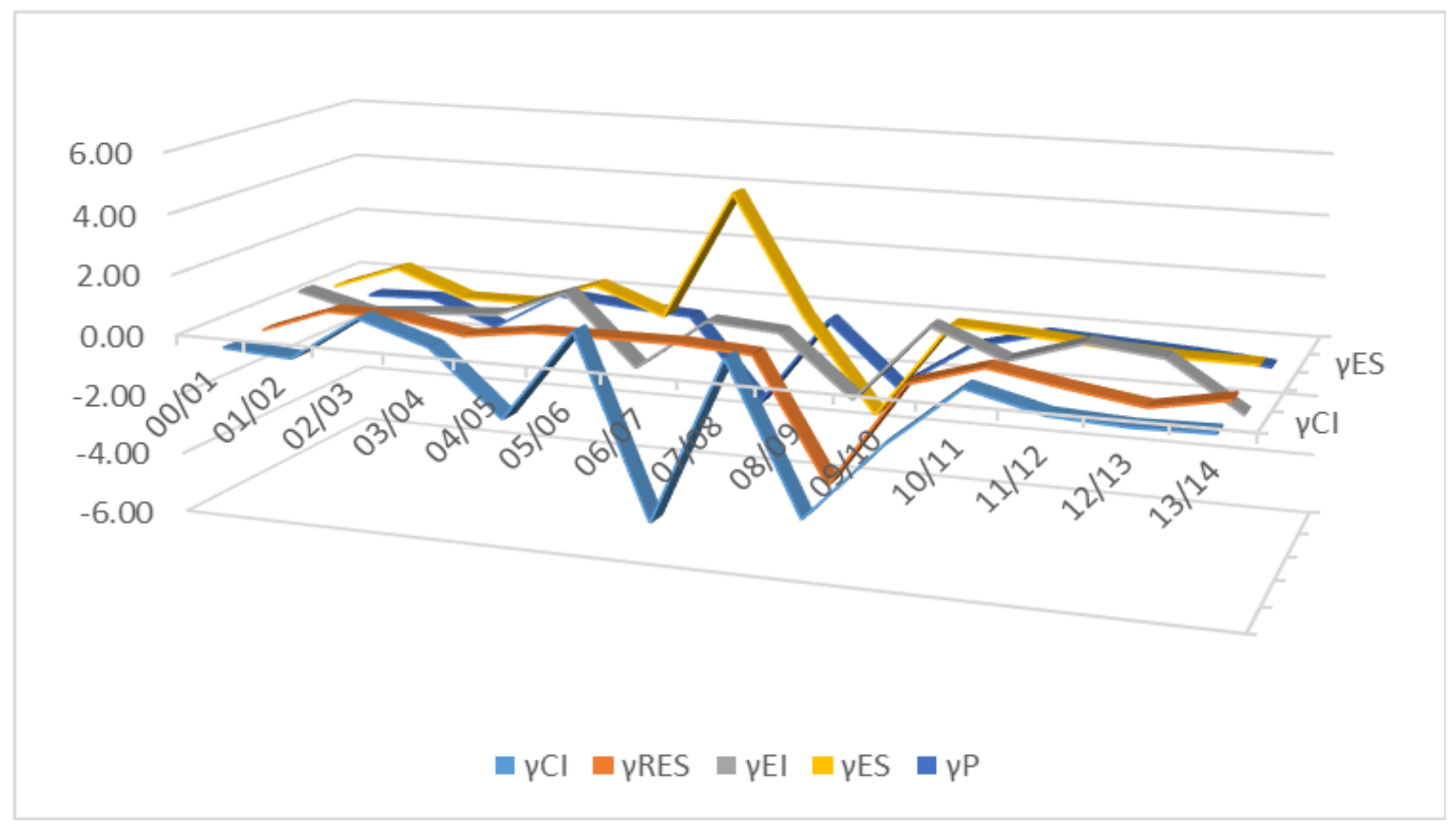

Figure 4. Decoupling index's trend.

Source: Own elaboration.

Table A.2 in annex gives detailed numerical values from which Figure 4 is built. When effects are considered all together, it can be seen that for most of the years under consideration, the decoupling index suggests that decoupling efforts did not overcome the role of the activity effect as a driver of 
$\mathrm{CO}_{2}$ emissions in Ecuador. This ex-post analysis flows in line with the role played by the same effect in the ex-ante analysis based on IRFs.

For most of the year, the Energy Intensity effect showed positive value, thus implying its role as an inhibitor of $\mathrm{CO}_{2}$ emissions. The economic structure effect shows a similar trend and this is relevant when considering how many of the effects react to a shock derived from this effect. Despite these optimistic results, when we observed CI and RES effect values, the optimistic level seemed to be damaged. However, drought as an uncontrollable climatic event ought to be considered when analyzing CI and RES effect values in the decoupling analysis, as it has a direct impact on hydroelectricity. These are the cases in 2005, 2009, 2010 and 2013 when electricity from hydropower plants decreased, thus pushing the Carbon Intensity effect to take negative values in the decoupling index when it is decomposed. Together with the other effects, the total value of the decoupling index is affected by the Population effect which acted against decoupling for all the years under consideration, as was expected.

A sectoral perspective of the decoupling process in Ecuador is provided in Figure 5 where information appears disaggregated by sectors.

(Figure 5) 


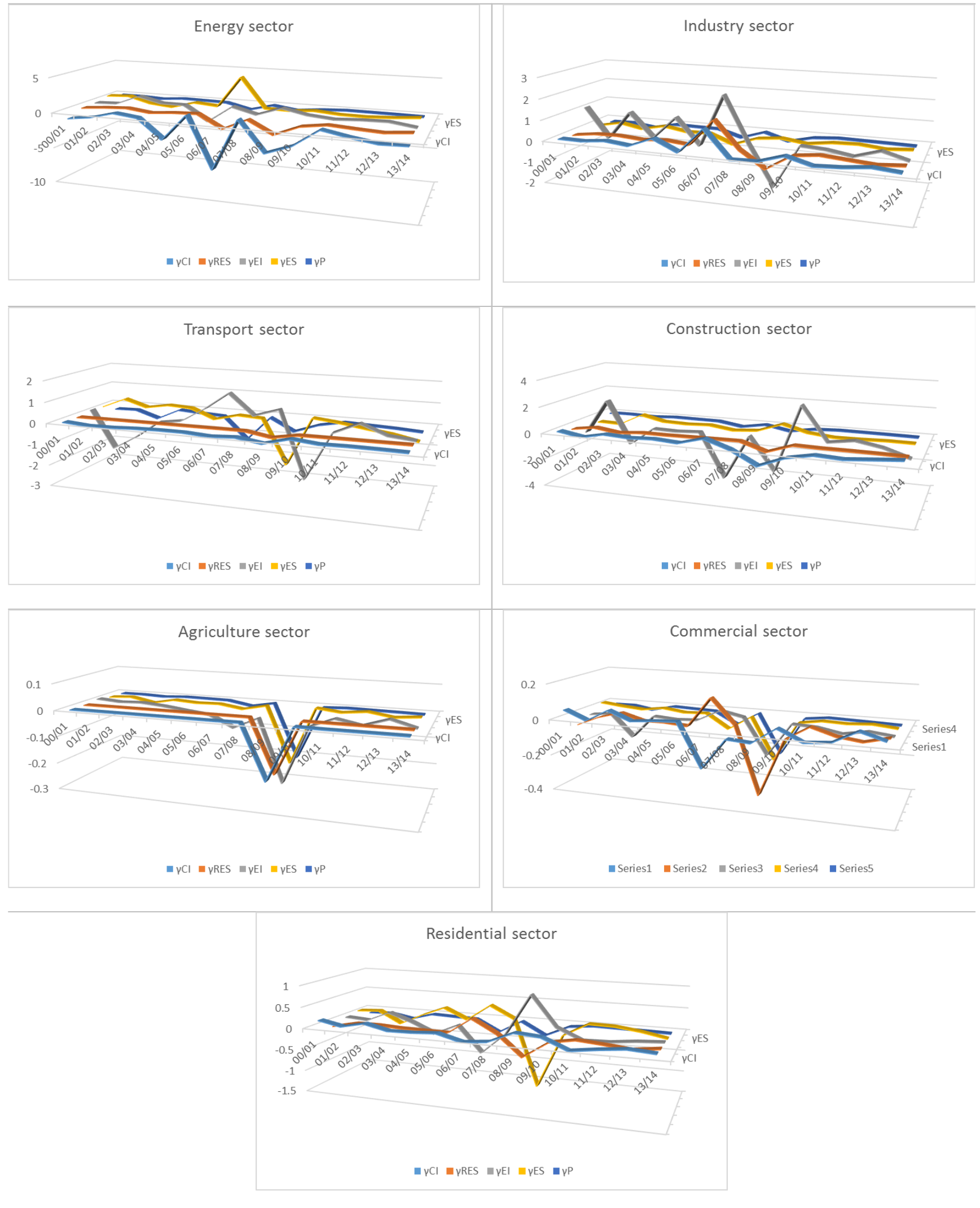

Figure 5. Disaggregated perspective of decoupling process. 
A sectoral perspective for the decoupling process identifies four sectors acting against decoupling between environmental stress and economic growth. Those are the energy, construction, commercial and agricultural sectors (although this later with a low weight sector). The only sector favoring decoupling was the Residential sector while Industry and Transportation did not show a clear pattern with years acting against decoupling and others favoring it.

For all sectors, the Population effect acted, as was expected, against decoupling. The Energy efficiency effect is the main responsive in the role played by the Residential sector to favor decoupling. This effect also acted as an inhibitor in the Industrial and the Energy sectors, but failed in Construction and Commercial sectors. This means that measures energy efficiency oriented in these latter sectors has to be re-thought. Finally, despite being sectors acting against decoupling (Construction and Commerce) or without a clear pattern (Industry) Carbonization Effect played an inhibitor role, although not enough to overcome the rest of the effects with a negative sign. Table A.3 in annex offers details for sectoral analysis.

\section{Conclusions and policy recommendations}

From 2000 to 2014, the main drivers explaining the changes in Ecuador's $\mathrm{CO}_{2}$ emissions were carbon intensity (CI), population and economic activity effect. Despite the fact that these acted as an inhibitor effect, improvements in energy intensity did not overcome the whole effects of the drivers. From a sectoral perspective, the energy and transportation sectors revealed as the most responsive for increased $\mathrm{CO}_{2}$ emissions. These conclusions derive from the first ex-post analysis conducted (LMDI). Results for the second ex-post analysis (decoupling index) support similar conclusions, thus highlighting the role of the energy sector acting against decoupling between economic growth and $\mathrm{CO}_{2}$ emissions

All of these results leads us to conclude that efforts should focus on a de-carbonization roadmap to remove fossil fuels from the core of Ecuador's energy matrix. Population consumption patterns need to move to more suitable options, including becoming prosumers. Together with this, the role played by the economic activity effect as one of the main drivers of $\mathrm{CO}_{2}$ emissions advices that Ecuador's economy remains far from the constitutional "Good Living" requirement as a paradigm oriented to reach decoupling between economic growth and environmental stress. 
The effectiveness of the efforts will be better if results from ex-ante analysis are taken into account. Consequently, there is bidirectional causality between the carbon intensity and the Energy Intensity effect. Those measures oriented towards technological advanced in energy would reduce the carbon intensity and $\mathrm{CO}_{2}$ emissions in Ecuador. One must consider that carbon intensity in the short term reacts more significantly to the Energy intensity effect. On other hand, bidirectional causality also appears between RES and EI in any efforts promoting RES will favor EI, thus helping to inhibit pollutants emissions.

Finally, we suggest a list of policy recommendations addressed as mitigation policies for Ecuador, which would also help reach a decoupling pathway between economic growth and $\mathrm{CO}_{2}$ emissions. Our recommendations are grouped together following the taxonomy of policy instruments available at Mundaca and Markandya (2016) but focused on Ecuador.

Economic incentives: We recommend that investment spending enjoy fiscal incentives in the form of corporate taxes. Investments need to be supervised by authorities and properly certified. Swedish corporate tax is a good example of how such fiscal incentives may be implemented. Investment spending should focus not only on reducing energy intensity, but also on $\mathrm{CO}_{2}$ sequestration technologies.

Regulatory approaches: To improve demand management it might be mandatory for electricity companies (generation companies and trading companies) to deploy a smart energy system by incorporating a) Smart meters, b) electricity with self-consumption capacity and 3) storage systems. Energy audits might be mandatory for those companies interested in working with Ecuador's authorities. At a sectoral level, due to the role played by the Transport sector, we recommend the use of new technologies installed in Smart phones oriented towards making car sharing easier. We also recommend an increase in the use of electric railways for the transportation of goods, if and when the electric matrix increases the participation of clean generation technologies. Increasing share of RES should be facilitated by a tendering system similar to those developed in other South American countries. Last mile problem might be anticipated, mainly in the largest cities. To enhance building codes, the current NEC-11 requirements need to be furthered, including requirements for materials and small-scale technologies need to be included in this regulatory approach. 
Information schemes: Due to there is major misunderstanding among citizens concerning the possibility of becoming prosumers by installing a domestic for self-energy consumption systems measures such as educational programs are recommended. Our recommendation is also to strengthen professional training, technical assistance and eco-efficiency labelling. This degree of misperception among citizens decreases in line with the educational level.

\section{Acknowledgements}

The first and second authors wish to acknowledge the funding provided by the following institutions: the Andalusian Regional Government (project SEJ-132), the "Cátedra de Economía de la Energía y del Medio Ambiente" sponsored by Red Eléctrica de España at the University of Seville," from Departamento de Análisis Económico y Economía Política (Department of Economic Analysis and Political Economy (Universidad de Sevilla) at the University of Seville and are also grateful to the Spanish "Ministerio de Ciencia, Innovación y Universidades" for the financial support received from the research project (RTI2018-096725-B-I00). The first author also acknowledges the funding provided by the Universidad Autónoma de Chile (Chile).

\section{Funding}

This work was supported by FEDER/Ministerio de Ciencia e Innovación - Agencia Estatal de Investigación [grant number RTI2018-096725-B-I00]; Fondo Europeo de Desarrollo Regional (FEDER) and Consejería de Economía, Conocimiento, Empresas y Universidad de la Junta de Andalucía, Programa Operativo FEDER 2014-2020 [grant number US-1260925].

\section{References}

Almeida, D., 2013. Crecimiento Económico y Medio Ambiente: La Curva Ambiental de Kuznets para el Ecuador en el Periodo 1970-2010. Universidad Católica del Ecuador, Quito, Ecuador.

Ang, B.W., 2004. Decomposition analysis for policymaking in energy: which is the preferred method? Energy Policy 32, 1131-1139

Ang, B.W., 2005. The LMDI approach to decomposition analysis: a practical guide. Energy Policy, 33 (7), 867-871.

Ang, B.W., Choi, K.H., 1997. Decomposition of aggregate energy and gas emission intensities for industry: A refined Divisia index method. The Energy Journal 18(3), 59-73. 
Ang, B.W., Liu, F.L., 2001. A new energy decomposition method: perfect in decomposition and consistent in aggregation. Energy 26, 537-548.

Ang, B.W., Zhang, F.Q., Choi, K.H., 1998. Factorizing changes in energy and environmental indicators through decomposition. Energy 23, 489-495.

Azomahou, T., Laisney, F., Nguyen Van, P. 2005. Economic growth and $\mathrm{CO}_{2}$ emissions: A nonparametric approach. Paper No. 05-056. ZEW - Centre for European Economic Research Discussion. Available at: https://ssrn.com/abstract=776384

Brooks, C., 2014. Introductory econometrics for finance. Cambridge University Press, Cambridge.

Cansino, J.M., Moreno, R., 2017. Does forest matter regarding Chilean $\mathrm{CO}_{2}$ international abatement commitments? A multilevel decomposition approach. Carbon Management, 9(1), 924.

Cansino, JM; Sánchez-Braza, A.; Rodríguez-Arévalo, M.L. 2015. Driving forces of Spain's $\mathrm{CO}_{2}$ emissions: A LMDI decomposition approach, Renewable and Sustainable Energy Reviews 48, 749-759.

Cansino, J.M., Sánchez-Braza, A., Rodríguez-Arévalo, M.L., 2018. How can Chile move away from a high carbon economy? Energy Economics 69, 350-366.

Central Intelligence Agency, 2017. The World Factbook, Ecuador. Central Intelligence Agency, Washington, D.C. Available at: https://www.cia.gov/library/publications/the-worldfactbook/fields/2046.html

Chen, L., Yang, Z., 2015. A spatio-temporal decomposition analysis of energy-related $\mathrm{CO}_{2}$ emission growth in China. Journal of Cleaner Production 103, 49-60.

Comité Ejecutivo de la Norma Ecuatoriana de la Construcción, 2011. Decreto Ejecutivo 705 de 6 de Abril de 2011. Available at: https://inmobiliariadja.files.wordpress.com/2016/09/nec2011-cap-13eficiencia-energc3a9tica-en-la-construccic3b3n-en-ecuador-021412.pdf

Cuesta, R.L., 2018. La curva de Kuznets como herramienta para medir el desarrollo económico y el equilibrio ambiental: revisión sistemática. UTMACH, Unidad Académica de Ciencias Agropecuarias, Machala, Ecuador. Available at: http://repositorio.utmachala.edu.ec/handle/48000/12216

Diakoulaki, D., Mandaraka, M., 2007. Decomposition analysis for assessing the progress in decoupling industrial growth from $\mathrm{CO}_{2}$ emissions in the EU manufacturing sector. Energy Economics 29, 636-64.

Fernández-González, P.F., Landajo, M., Presno, M.J., 2014. Multilevel LMDI decomposition of changes in aggregate energy consumption. A cross country analysis in the EU-27. Energy Policy $68,576-584$.

Gevaers, R., Van de Voorde, E., Vanelslander, T., 2011. Characteristics and typology of last-mile logistics from an innovation perspective in an urban context. City Distribution and Urban Freight Transport: Multiple Perspectives, Edward Elgar Publishing, 56-71.

Gobierno Nacional de la República de Ecuador. 2015. Ecuador's Intended Nationally Determined Contribution (INDC). Available at: http://www4.unfccc.int/submissions/INDC/Published\%20Documents/Ecuador/1/Ecuador\%20INDC\%2 001-10-2015\%20-\%20english\%20unofficial\%20translation.pdf 
Goldemberg, J., Johansson, T.B. (Eds.), 2004. World Energy Assessment: Overview 2004 Update. UNDP, United Nations Development Program, New York. Available at: http://www.leonardoenergy.org/world-energy-assessment-overview-2004-update

Guo, B., Geng, Y., Franke, B., Hao, H., Liu, Y., Chiu, A., 2014. Uncovering China's transport $\mathrm{CO}_{2}$ emission patterns at the regional level. Energy Policy 74, 134-146.

International Renewable Energy Agency, 2015. Energías Renovables en América Latina 2015: Sumario de Políticas. Available at: https://www.irena.org//media/Files/IRENA/Agency/Publication/2015/IRENA_RE_Latin_America_Policies/IRENA_RE_Lati n_America_Policies_2015_ES.pdf?la=en\&hash=6356C4BE57790F648178E7A02B5823ECD54E5340

Jiang, X.T., Dong, J.F., Wang, X.M., Li, R.R., 2016. The Multilevel Index Decomposition of Energy-Related Carbon Emission and Its Decoupling with Economic Growth in USA. Sustainability 8, 857.

Jiménez, S., Castro, L., Yépez, J., Wittmer, C., 2012. Impacto del cambio climático en la agricultura de subsistencia en el Ecuador. Serie Avances de Investigación $n^{\circ} 66$. Fundación Carolina - CeALCI, Madrid. Available at: https://www.fundacioncarolina.es/wpcontent/uploads/2014/08/AI66.pdf

Maghyereh, A., 2004. Oil price shocks and emerging stock markets: A generalized VAR approach. International Journal of Applied Econometrics and Quantitative Studies 1(2), 27-40.

Ministry of Environment, 2016. Plan de Acción Nacional de Cambio Climático 2017-2022. Chilean Ministry of Environment, Santiago, Chile. Available at: https://mma.gob.cl/wpcontent/uploads/2016/04/Anteproyecto-PANCC-2017-2022-FINAL-2016-04-18.pdf

Morocho, S.C., 2018. Emisión de $\mathrm{CO}_{2}$ en la producción agrícola ecuatoriana y su relación con el producto interno bruto 2009-2014. UTMACH, Unidad Académica de Ciencias Agropecuarias, Machala, Ecuador. Available at: http://repositorio.utmachala.edu.ec/handle/48000/12220

Moutinho, V., Madaleno, M., Silva, P.M., 2016. Which factors drive $\mathrm{CO}_{2}$ emissions in EU-15? Decomposition and innovative accounting. Energy Efficiency 9(5), 1087-1113.

Mundaca, L., Markandya, A., 2016. Assessing regional progress towards a 'Green Energy Economy’. Applied Energy 179, 1372-1394.

Naciph, K., Rivadeneira, L., Cazorla, M., 2013. Cálculo de las emisiones de $\mathrm{CO}_{2}$ de la Universidad San Francisco de Quito pertenecientes al rubro de transporte estudiantil del Segundo Semestre 2012-2013. ACI Avances en Ciencias e Ingenierías 5(2), C1-C4.

O'Mahony, T., 2013. Decomposition of Ireland's carbon emissions from 1990 to 2010: An extended Kaya identity. Energy Policy 59, 573-581.

Ozkan, F., Ozkan, O., 2012. An analysis of $\mathrm{CO}_{2}$ emissions of Turkish industries and energy sector. Regional and Sectoral Economic Studies 12(2), 65-85.

Park, J., Ratti, R.A., 2008. Oil price shocks and stock markets in the US and 13 European countries. Energy Economics 30(5), 2587-2608.

Parra, R., 2015. Factor de emisión de $\mathrm{CO}_{2}$ debido a la generación de electricidad en el Ecuador durante el período 2001-2011. Avances 5(1), C39-C42. 
Rentería, V., Toledo, E., Bravo-Benavides, D., Ochoa-Jiménez, D., 2016. Relación entre Emisiones Contaminantes, Crecimiento Económico y Consumo de Energía. El caso de Ecuador 1971-2010. Revista Politécnica 38(1), 7pp.

Robaina-Alves, M., Moutinho, V., 2013. Decomposition analysis and Innovative Accounting Approach for energy-related $\mathrm{CO}_{2}$ (carbon dioxide) emissions intensity over 1996-2009 in Portugal. Energy 57(1), 775-787.

Robalino-López, A., Mena-Nieto, A., García-Ramos, J.E., 2014a. System dynamics modeling for renewable energy and $\mathrm{CO}_{2}$ emissions: A case study of Ecuador. Energy for Sustainable Development 20, 11-20.

Robalino-López, A., García-Ramos, J. E., Golpe, A.A., Mena-Nieto, Á., 2014b. System dynamics modelling and the environmental Kuznets curve in Ecuador (1980-2025). Energy Policy 67, 923-931.

Roinioti, A., Koroneos, C., 2017. The decomposition of $\mathrm{CO}_{2}$ emissions from energy use in Greece before and during the economic crisis and their decoupling from economic growth. Renewable and Sustainable Energy Reviews 76, 448-459.

Román-Collado, R., Cansino, J. M., Botia, C. 2018a. How far is Colombia from decoupling? Twolevel decomposition analysis of energy consumption changes. Energy 148, 687-700.

Román-Collado, R., Cansino, J.M., Molina, J.C. 2018b. Quality governance, Income and technological progress' impact on Latin American $\mathrm{CO}_{2}$ emissions. 41st edition of the IAEE international conference. Groningen, The Netherland, June, 9-13 th. http://iaee2018.com/

Salazar, G., Panchi, B. 2014. Análisis de la evolución de la demanda eléctrica en el Ecuador considerando el ingreso de proyectos de eficiencia energética. Revista Politécnica 33(3), 10pp.

Schor, J. 2016. Debating the sharing economy. Journal of Self-Governance and Management Economics 4(3), 7-22.

Shahbaz, M., Hye, Q.M.A., Tiwari, A.K., Leitão, N.C., 2013. Economic growth, energy consumption, financial development, international trade and $\mathrm{CO}_{2}$ emissions in Indonesia. Renewable and Sustainable Energy Reviews (25), 109-121.

Shahiduzzaman, M., Layton, A. 2015. Decomposition analysis to examine Australia's 2030 GHGs emissions target: How hard will it be to achieve? Economic Analysis and Policy 48, 25-34.

Somuncu, T., Hannum, C. 2018. The Rebound effect of energy efficiency policy in the presence of energy theft. Energies 11(12), 3379.

Sumabat, A.K., Lopez, N.S., Yu, K.D., Hao, H., Li, R., Geng, Y., Chiu, A.S., 2016. Decomposition analysis of Philippine $\mathrm{CO}_{2}$ emissions from fuel combustion and electricity generation. Applied Energy 164, 795-804.

Tapio, P., 2005. Towards a theory of decoupling: degrees of decoupling in the EU and the case of road traffic in Finland between 1970 and 2001. Transport Policy 12, 137-151.

The World Bank, 2018. World Development Indicators 2018, Ecuador. World Bank Group. Available at: https://data.worldbank.org/products/wdi 
Timilsina, G., Shrestha, A., 2009. Factors affecting transport sector $\mathrm{CO}_{2}$ emissions growth in Latin Americ and Caribbean countries: An LMDI decomposition analysis. International Journal of Energy Research 33(4), 396-414.

UNDP, 2016. Human Development Report 2016. Ecuador. United Nations Development Programme. Available at: http://hdr.undp.org/sites/all/themes/hdr_theme/country-notes/ECU.pdf

UNEP, 2011. Decoupling Natural Resource use and Environmental Impacts From Economic Growth [ebook]. United Nations Environment Programme, Paris, (Available) 〈http://www.unep.org/resourcepanel/decoupling/files/pdf/decoupling_report_english.pdf

Viteri, A.C., 2015. The Ecuador National Plan of 'Buen Vivir' and the Possible Contradictions that Arise from the End of the Yasuni ITT Initiative (Master's thesis, Australia/Universidad de Melbourne).

Voigt, S., De Cian, E., Schymura, M., Verdolini, E., 2014. Energy intensity developments in 40 major economies: Structural change or technology improvement? Energy Economics 41, 47-62.

Walters, J.P., Kaminsky, J., Huepe, C., 2018. Factors Influencing Household Solar Adoption in Santiago, Chile. Journal of Construction Engineering and Management, 144(6), 05018004.

Wang, Q., Jiang, R., Li, R., 2016. Decoupling and decomposition analysis of carbon emissions from industry: Case study of China. Sustainability 8, 1059.

Wilmsmeier, G., Guidry, L., 2013. Evolución de la distribución modal del transporte de mercancías en América del Sur. Santiago CEPAL 2013-09. Available at: https://repositorio.cepal.org/handle/11362/37619

Zambrano-Monserrate, M.A., García, F.F., Henk-Vera, K.A., 2016. Bounds testing approach to analyze the existence of an environmental Kuznets curve in Ecuador. International Journal of Energy Economics and Policy 6(2), 159-166.

Zhang, M., Mu, H., Ning, Y., Song, Y., 2009. Decomposition of energy-related $\mathrm{CO}_{2}$ emission over 1991-2006 in China. Ecological Economics 68, 2122-2128. 


\section{Annex}

Table A.1. Descriptive stats

Sample: 20012014

\begin{tabular}{lcccrrr}
\hline \hline & CI & EA & EI & ES & \multicolumn{1}{c}{ RES } & \multicolumn{1}{c}{ P } \\
\hline \hline Mean & 300.5169 & 934.3352 & -139.1819 & -178.8102 & 26.18849 & 553.9773 \\
Median & 361.3757 & 878.5109 & -137.4860 & -71.92590 & -38.71667 & 555.8188 \\
Maximum & 2118.123 & 2319.538 & 1071.563 & 710.5548 & 1109.017 & 680.4099 \\
Minimum & -901.2356 & -386.7628 & -1199.867 & -836.0961 & -855.2257 & 450.6401 \\
Std. Dev. & 869.2653 & 707.4823 & 658.8014 & 403.9059 & 448.7121 & 80.49613 \\
Skewness & 0.336855 & 0.122708 & 0.284018 & 0.272257 & 0.580059 & 0.003780 \\
Kurtosis & 2.595737 & 2.669667 & 2.668669 & 2.934435 & 4.222401 & 1.622164 \\
& & & & & & \\
Jarque-Bera & 0.360099 & 0.098787 & 0.252259 & 0.175463 & 1.656747 & 1.107452 \\
Probability & 0.835229 & 0.951807 & 0.881501 & 0.916007 & 0.436759 & 0.574804 \\
Sum & & & & & & \\
Sum Sq. Dev. & 9823089.237 & 13080.69 & -1948.546 & -2503.342 & 366.6388 & 7755.682 \\
Observations & 14 & 6506906. & 5642251. & 2120820. & 2617454. & 84235.15 \\
\hline
\end{tabular}




\section{Table A. 2}

Table A.2. Decomposition values

\begin{tabular}{|c|c|c|c|c|c|c|c|c|c|c|c|c|c|c|}
\hline & $00 / 01$ & $01 / 02$ & $02 / 03$ & $03 / 04$ & $04 / 05$ & $05 / 06$ & $06 / 07$ & 07/08 & 08/09 & 09/10 & $10 / 11$ & $11 / 12$ & $12 / 13$ & $13 / 14$ \\
\hline$\gamma_{\mathrm{CI}}$ & -0.50 & -0.66 & 0.87 & 0.13 & -2.01 & 1.05 & -4.90 & 0.61 & -4.26 & -1.72 & 0.33 & -0.27 & -0.40 & -0.34 \\
\hline$\gamma_{\mathrm{RES}}$ & -0.46 & 0.37 & 0.35 & -0.06 & 0.27 & 0.27 & 0.29 & 0.14 & -3.87 & -0.37 & 0.37 & -0.06 & -0.43 & 0.04 \\
\hline$\gamma_{\mathrm{EI}}$ & 0.37 & -0.21 & -0.02 & 0.11 & 1.04 & -1.29 & 0.47 & 0.30 & -1.70 & 0.91 & -0.01 & 0.77 & 0.50 & -1.08 \\
\hline$\gamma_{\mathrm{ES}}$ & 0.02 & 0.85 & -0.02 & -0.01 & 0.79 & -0.08 & 4.27 & 0.25 & -2.84 & 0.40 & 0.27 & 0.08 & -0.06 & -0.07 \\
\hline$\gamma_{\mathrm{P}}$ & -0.81 & -0.73 & -1.59 & -0.26 & -0.47 & -0.64 & -3.54 & -0.38 & -2.51 & -0.90 & -0.27 & -0.41 & -0.54 & -0.74 \\
\hline$\gamma$ & -1.38 & -0.38 & -0.41 & -0.09 & -0.38 & -0.68 & -3.41 & 0.91 & -16.18 & -1.68 & 0.70 & 0.12 & -0.93 & -2.20 \\
\hline
\end{tabular}


Table A.3

Table A.3 Decomposition analysis in figures

\begin{tabular}{|c|c|c|c|c|c|c|c|c|c|c|c|c|c|c|c|}
\hline & SECTOR & 2000/2001 & $2001 / 2002$ & $2002 / 2003$ & $2003 / 2004$ & $2004 / 2005$ & $2005 / 2006$ & 2006/2007 & $2007 / 2008$ & $2008 / 2009$ & $2009 / 2010$ & 2010/2011 & 2011/2012 & $2012 / 2013$ & 2013/2014 \\
\hline \multirow{8}{*}{$\gamma_{\mathrm{CI}}$} & Energy sector & -0.92 & -0.50 & 0.36 & -0.04 & -2.75 & 0.91 & -6.25 & 0.89 & -3.31 & -2.03 & 0.40 & -0.26 & -0.79 & -0.69 \\
\hline & Industry sector & 0.06 & 0.05 & 0.17 & 0.04 & 0.50 & -0.03 & 1.15 & -0.14 & -0.10 & 0.26 & -0.05 & 0.00 & 0.13 & 0.02 \\
\hline & Transport sector & 0.02 & -0.07 & -0.06 & -0.01 & 0.01 & 0.01 & -0.07 & -0.01 & -0.18 & 0.13 & 0.00 & 0.02 & 0.01 & -0.01 \\
\hline & Others & 0.11 & -0.20 & 0.16 & 0.06 & 0.14 & 0.02 & 0.52 & -0.11 & -1.08 & -0.33 & 0.04 & -0.06 & 0.10 & 0.25 \\
\hline & $\begin{array}{l}\text { Commercial and } \\
\text { Public sectors }\end{array}$ & 0.05 & 0.00 & 0.07 & 0.02 & 0.03 & 0.03 & -0.21 & -0.04 & -0.05 & 0.04 & -0.02 & -0.01 & 0.06 & 0.02 \\
\hline & Agriculture sector & 0.00 & 0.00 & 0.00 & 0.00 & 0.00 & 0.00 & 0.00 & 0.00 & -0.20 & 0.00 & 0.00 & 0.00 & 0.00 & 0.00 \\
\hline & Residential sector & 0.17 & 0.06 & 0.18 & 0.06 & 0.06 & 0.10 & -0.05 & 0.00 & 0.25 & 0.20 & -0.03 & 0.04 & 0.10 & 0.06 \\
\hline & TOTAL & -0.50 & -0.66 & 0.87 & 0.13 & -2.01 & 1.05 & -4.90 & 0.61 & -4.26 & -1.72 & 0.33 & -0.27 & -0.40 & -0.34 \\
\hline \multirow{8}{*}{$\gamma_{\mathrm{RES}}$} & Energy sector & -0.10 & 0.17 & 0.34 & -0.07 & 0.20 & 0.32 & -1.51 & 0.06 & -1.72 & -0.30 & 0.18 & -0.06 & -0.24 & 0.07 \\
\hline & Industry sector & -0.04 & 0.10 & 0.13 & 0.04 & 0.12 & 0.00 & 1.28 & -0.01 & -0.78 & -0.04 & 0.09 & -0.01 & -0.11 & -0.02 \\
\hline & Transport sector & 0.00 & 0.00 & 0.00 & 0.00 & 0.00 & 0.00 & 0.00 & 0.00 & -0.20 & 0.00 & 0.00 & 0.00 & 0.00 & 0.00 \\
\hline & Others & -0.16 & 0.09 & -0.16 & -0.01 & -0.02 & 0.00 & 0.02 & 0.03 & -0.58 & 0.06 & 0.02 & 0.01 & 0.00 & -0.04 \\
\hline & $\begin{array}{l}\text { Commercial and } \\
\text { Public sectors }\end{array}$ & -0.06 & -0.01 & 0.03 & -0.01 & -0.01 & -0.02 & 0.15 & 0.01 & -0.37 & -0.05 & 0.03 & -0.01 & -0.03 & 0.01 \\
\hline & Agriculture sector & 0.00 & 0.00 & 0.00 & 0.00 & 0.00 & 0.00 & 0.00 & 0.00 & -0.20 & 0.00 & 0.00 & 0.00 & 0.00 & 0.00 \\
\hline & Residential sector & -0.10 & 0.02 & 0.02 & -0.01 & -0.02 & -0.03 & 0.35 & 0.05 & -0.43 & -0.04 & 0.05 & 0.01 & -0.05 & 0.02 \\
\hline & TOTAL & -0.46 & 0.37 & 0.35 & -0.06 & 0.27 & 0.27 & 0.29 & 0.14 & -3.87 & -0.37 & 0.37 & -0.06 & -0.43 & 0.04 \\
\hline \multirow{7}{*}{$\gamma_{\mathrm{EI}}$} & Energy sector & -0.03 & 0.09 & 1.42 & 0.63 & 0.60 & -1.47 & 0.89 & 0.02 & 1.18 & 0.47 & 0.16 & 0.35 & 0.40 & -0.10 \\
\hline & Industry sector & 1.10 & -0.36 & 1.01 & -0.15 & 0.94 & -0.33 & 2.19 & -0.04 & -1.99 & 0.09 & 0.02 & -0.18 & 0.19 & -0.15 \\
\hline & Transport sector & 0.14 & -1.71 & -1.06 & -0.24 & -0.07 & 0.60 & 1.42 & 0.45 & 0.82 & -2.33 & -0.07 & 0.46 & 0.00 & -0.11 \\
\hline & Others & -0.83 & 1.82 & -1.46 & -0.13 & -0.18 & -0.07 & -3.44 & -0.05 & -2.54 & 2.55 & -0.02 & 0.26 & -0.08 & -0.69 \\
\hline & $\begin{array}{l}\text { Commercial and } \\
\text { Public sectors }\end{array}$ & -0.03 & -0.02 & -0.14 & -0.01 & -0.02 & -0.01 & 0.05 & 0.02 & -0.18 & 0.01 & 0.00 & -0.03 & 0.00 & -0.02 \\
\hline & Agriculture sector & 0.01 & 0.00 & 0.00 & 0.00 & -0.01 & -0.02 & -0.07 & -0.02 & -0.26 & -0.04 & 0.00 & -0.02 & 0.01 & -0.02 \\
\hline & Residential sector & 0.01 & -0.02 & 0.21 & 0.02 & -0.22 & 0.03 & -0.58 & -0.08 & 0.86 & 0.16 & -0.09 & -0.08 & -0.02 & 0.02 \\
\hline
\end{tabular}


Figure A.1

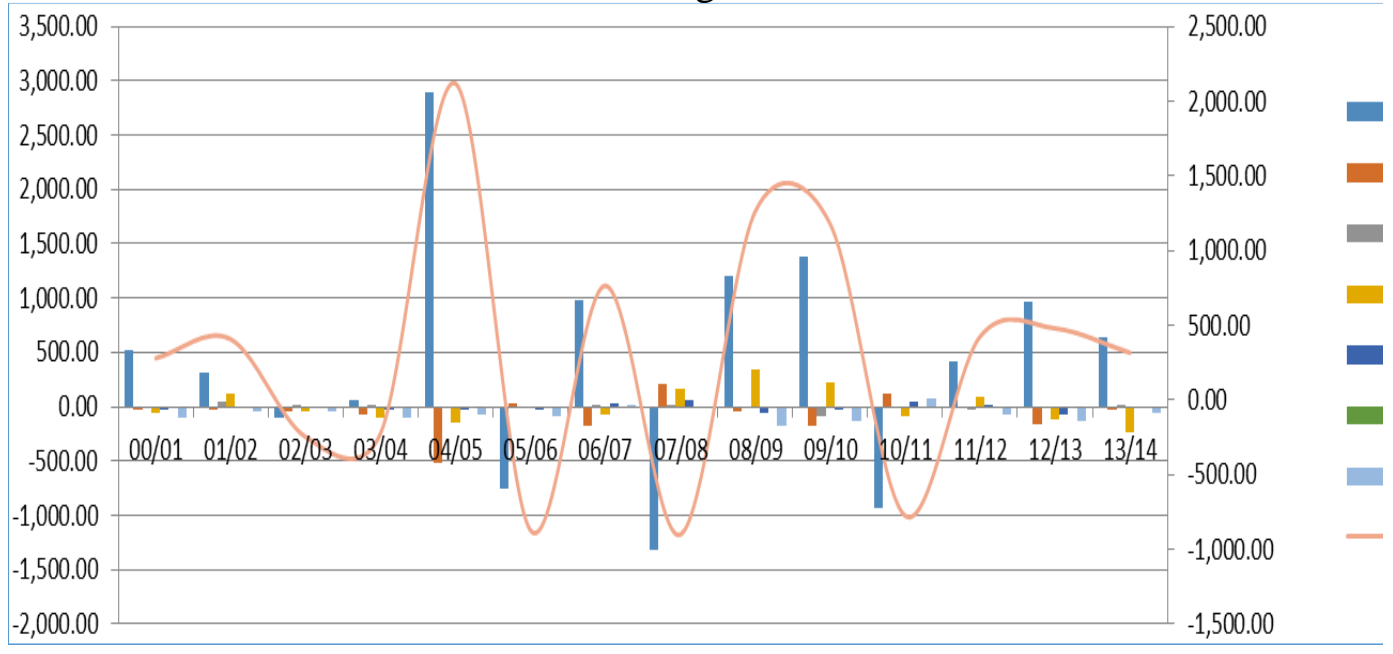

Fig. A.1.1. CI effect

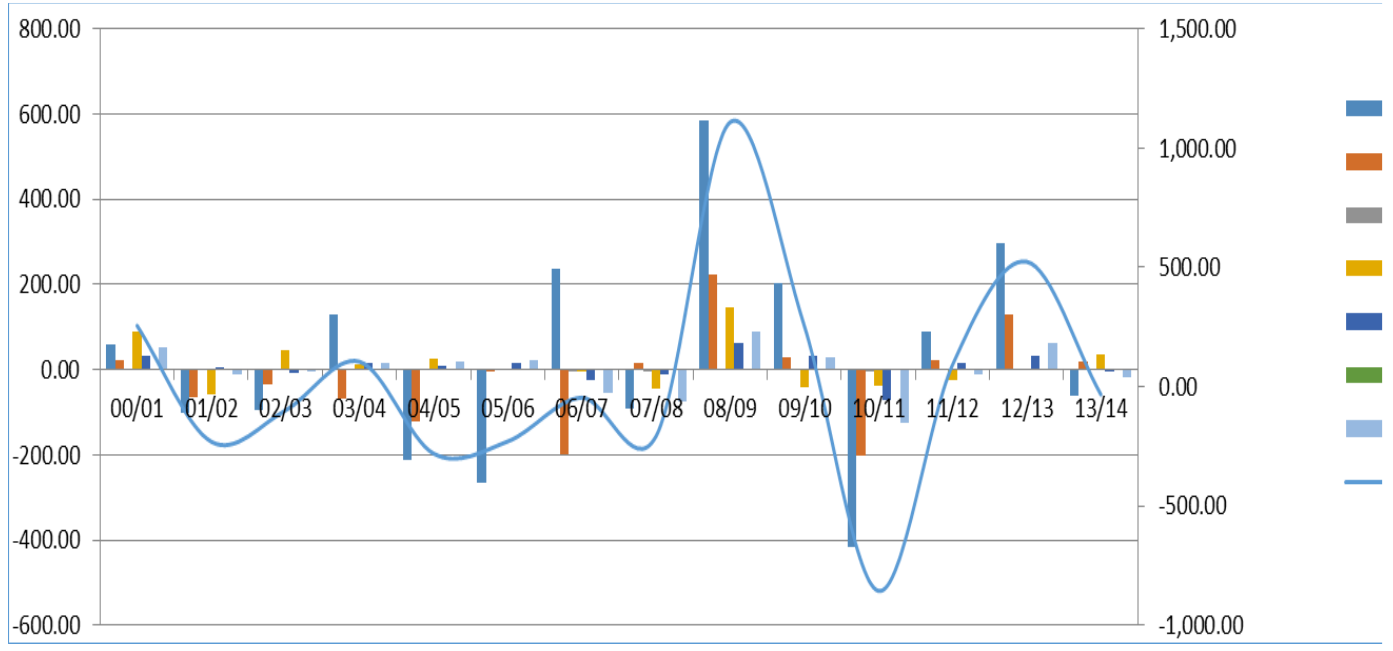

Fig. A.1.2. RES effect

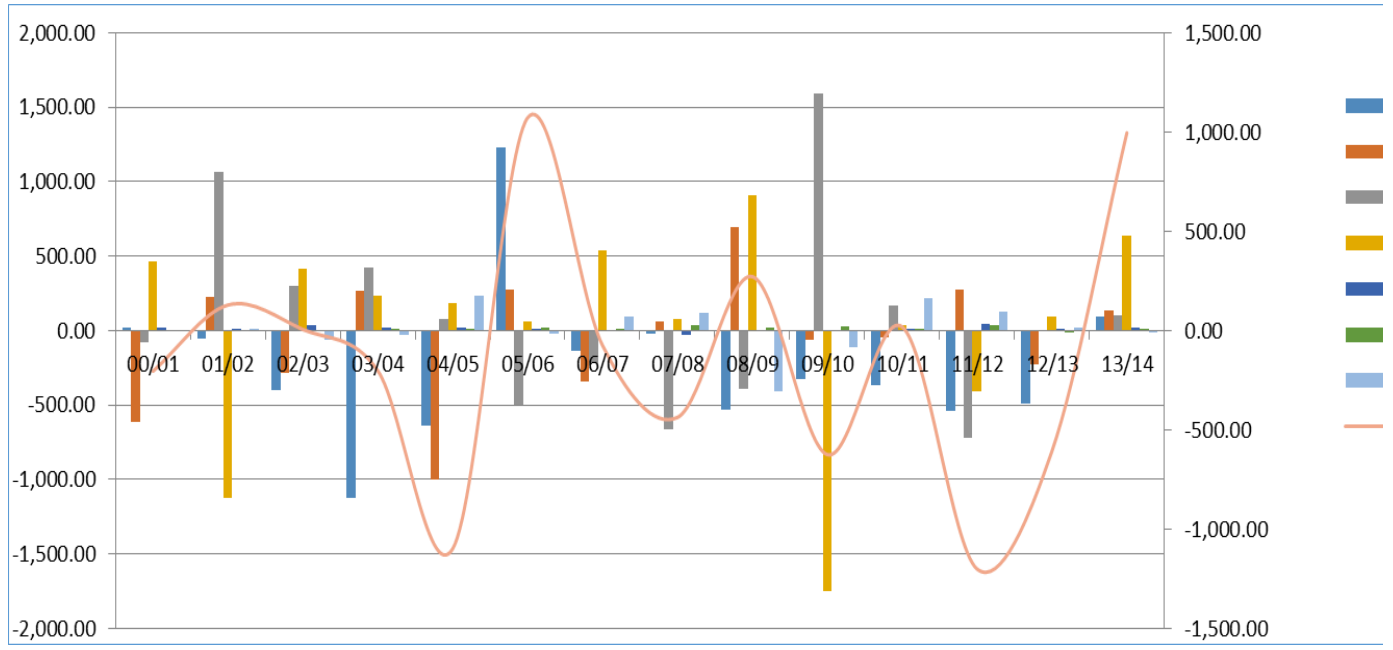

Fig. A.1.3. EI effect 